\title{
Combined antihypertensive effect of unripe Rubus coreanus Miq. and Dendropanax morbiferus H. Lév. Extracts in 1 kidney-1 clip hypertensive rats and spontaneously hypertensive rats
}

Soyi Park ${ }^{1}$, Ki Hoon Lee ${ }^{1}$, Hakjoon Choi ${ }^{1}$, Goeun Jang ${ }^{1}$, Wan Seok Kang ${ }^{1}$, Eun Kim ${ }^{1}$, Jin Seok Kim', Chang-su $\mathrm{Na}^{2}$ and Sunoh Kim${ }^{1 *}$ (D)

\begin{abstract}
Background: We previously showed that enzymatically hydrolyzed Dendropanax morbiferus H. Lév. leaf (Hy-DP) and unripe Rubus coreanus Miq. (5-uRCK) extracts exhibit potent vasodilator effects on isolated aortic rings from rats partly through endothelium-dependent and endothelium-independent mechanisms. These two extracts have different mechanisms of action; however, their combined effect on antihypertensive activity has not been explored.

Methods: The present study aims to investigate the effect of a chronic optimized mixture (HDR-2, composed of Hy-DP and 5-uRCK in a 2:1 mass ratio) on vascular tension and blood pressure in two different hypertensive rat models.
\end{abstract}

Results: The results showed that HDR-2 concentration-dependently relaxed endothelium-intact and endotheliumdenuded aortic rings precontracted with phenylephrine. Antihypertensive effects were assessed in vivo on a 1 kidney-1 clip (1 K-1C) rat model of hypertension and spontaneously hypertensive rats (SHRs). Acute HDR-2 treatment significantly decreased systolic blood pressure (SBP) $3 \mathrm{~h}$ posttreatment in both models. Chronic HDR-2 administration also significantly decreased SBP in the hypertensive rat models. Moreover, HDR-2 increased eNOS protein expression and phosphorylation levels in the aorta.

Conclusion: Chronic HDR-2 administration may effectively improve vascular function by decreasing plasma angiotensin-converting enzyme (ACE) activity and Angll levels. HDR-2 significantly improved acetylcholine (ACh)-induced aortic endothelium-dependent relaxation and affected sodium nitroprusside (SNP)-induced endothelium-independent relaxation in SHRs.

Keywords: Enzymatically hydrolyzed Dendropanax morbiferus H. Lév., Unripe Rubus coreanus Miq., 1 kidney-1 clip hypertensive rat, Spontaneously hypertensive rat, Hypertension

*Correspondence: sunoh@korea.ac.kr

${ }^{1}$ Central R\&D Center, Bioresources and Technology (B\&Tech) Co., Ltd., 257,

Jebong-ro, Buk-gu, Gwangju 61239, South Korea

Full list of author information is available at the end of the article

\section{Background}

High blood pressure is one of the major risk factors for the development of vascular diseases such as atherosclerosis, coronary heart disease and stroke [1], and several studies have reported cardiovascular risks associated 
with elevated blood pressure [2, 3]. Hypertension, a global public health risk, is highly associated with heart disease, stroke, kidney failure, premature death and disability [4]. Currently, many antihypertensive therapeutic drugs have been developed and are now available for use in clinical treatment, including thiazide diuretics, $\beta$-blockers, renin-angiotensin-aldosterone system (RAAS) inhibitors and $\mathrm{Ca}^{2+}$ channel blockers. However, side effects have been reported with these treatments. Thiazide diuretics could potentially result in insulin resistance, dyslipidemia and hyperuricemia, which would accelerate diabetes progression in patients with obesity and metabolic syndromes [5]. Traditional $\beta$-blockers also appear to have a significantly higher risk of diabetes. RAAS inhibitors, by angiotensin-converting enzyme (ACE) inhibitors or an angiotensin receptor blocker (ARB) along with $\mathrm{Ca}^{2+}$ channel blockers, appear to have improved safety properties, but some of them still have various side effects, such as coughing, taste disturbance and skin rashes [6]. Clearly, future investigations for novel and safe antihypertensive drugs are still required.

Dendropanax morbiferus $\mathrm{H}$. Lév. is an endemic tree species in Korea belonging to the family Araliaceae, and extracts are traditionally used to treat various diseases [7]. Active chemicals in D. morbiferus leaf extract $(D P)$ have also various biological effects [8-11]. Furthermore, we reported the change in the content of quercetin, a marker chemical, depending on the parts, harvest season, and extraction methods of D. morbiferus for quality control [12]. Quercetin and its metabolites, such as 3-(3-hydroxyphenyl)propionic acid (3HPPA), 3,4-dihydroxyphenylacetic acid (DHPA) and 4-methylcatechol (4MC), administered orally are well known to be able to decrease arterial blood pressure [13-15]. Another our previous study reported that we developed a technique to increase ${ }_{L}$-arginine and $\gamma$-aminobutyric acid (GABA) levels of $D P$ by enzymatic hydrolysis (producing Hy- $D P$ )

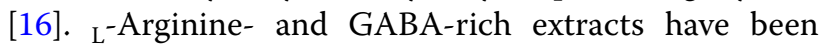
demonstrated to reduce blood pressure in clinical studies $[17,18]$. GABA, contained in various foods, has been suggested to be a major component regulating cardiovascular function and hypertension [19-23]. Furthermore, in our previous study, $D P$ and $\mathrm{Hy}-D P$ dose-dependently relaxed endothelium-intact aortic rings precontracted with phenylephrine (PHE). Between them, Hy-DP exhibited the more potent vascular relaxant effect [24].

The Rubus genus comprises thousands of species of blackberries and raspberries grown worldwide, and species in this genus have been investigated as novel therapeutic agents for metabolic syndrome through their beneficial effects [25]. One such species, Rubus coreanus Miquel, which is native to eastern Asia, has been used as a traditional alternative medicine to manage impotence, spermatorrhea, enuresis, asthma and allergic diseases [26]. The major active chemical in $R$. coreanus is ellagic acid, which has multi-biological properties [27, 28]. According to a report, it is suggested that the concentration of ellagic acid, the main active compound of $R$. coreanus, is higher in immature stage than in the mature stage [29]. In particular, comparing the efficacy of each extracts according to various extraction methods of unripe $R$. coreanus, $5 \%$ ethanol extract of unripe $R$. coreanus (5-uRCK) has the best effect on hyperlipidemia [30, $31]$, obesity [32, 33] and hypertension [24] reported, and interestingly, it was confirmed that the content of ellagic acid was the highest through this extraction method $[24,31,33]$. Thus, our previous studies in animal models demonstrated that $5-u$ RCK exerts antihypercholesterolemic, antiobesity and vasorelaxant effects.

Very recently, we scientifically validated that $\mathrm{Hy}-D P$ and 5-uRCK are involved in endothelial-dependent and endothelial-independent relaxation in the aortic ring [24]. Furthermore, we screened for various efficacies (ACE activity, cGMP dependent-PDE activity, cAMP dependent-PDE activity, and vasorelaxation) in mixtures of various mixing ratios $(1: 0,1: 1,1: 2,1: 3,2: 1,3: 1$ and $0: 1)$ of Hy-DP and 5-uRCK. Interestingly, when Hy-DP and 5- $u$ RCK were mixed in a specific ratio of 2:1 (producing HDR-2), the greatest vasodilatory effect was shown. However, more research is required to evaluate the detailed mechanisms in experimental animal models of hypertension. In this work, therefore, we intend to conduct further studies to elucidate the detailed mechanism using two different hypertensive animal models, namely, the spontaneously hypertensive rat (SHR) model, an established model of genetic hypertension, and the 1 kidney-1 clip (1 K-1C) Goldblatt rat model of hypertension.

\section{Methods \\ Reagents}

All the chemicals were purchased from Sigma-Aldrich (St. Louis, MO, USA) or Tocris (Ellisville, MO, USA). All the media components were purchased from Invitrogen, Inc. (Grand Island, NY, USA).

\section{Preparation of extracts}

The unripe $R$. coreanus fruits used in this study were collected (May 2017) in Gochang-gun (Jeollabukdo, Korea). Extracts of the unripe $R$. coreanus were described in our previous study [24, 30-33]. The dried leaves of $D$. morbiferus used in this study were collected (December 2017) in Gangjin-gun (Jeollanamdo, Korea) and Hy-DP extraction was performed as described in our previous study [16, 24]. HDR-2 consisted of an optimized mixture of compounds derived from $\mathrm{Hy}-D P$ and 5- $u \mathrm{RCK}$. 


\section{Animals}

Healthy male Sprague-Dawley rats (S-D rats, $n=20$ ) were used for the ex vivo aortic ring experiments, male Wistar rats ( $n=42$, weighing 250 to $300 \mathrm{~g}$ each) were used for the $1 \mathrm{~K}-1 \mathrm{C}$ hypertensive rat model experiments, and five-week-old male SHRs $(n=20)$ and normotensive male Wistar Kyoto rats (WKY, $n=5$ ) were used for the blood pressure experiments. All animals were purchased from Central Lab Animal, Inc. (Seoul, Republic of Korea). The experiment was conducted according to the international guidelines [34] and was approved by the institutional animal care and use committee (IACUC) of the B\&Tech Co., Ltd., Korea (Approval number: BT-002-2018).

\section{Induction of 1-kidney, 1-clip Goldblatt hypertensive $(1 \mathrm{~K}-1 \mathrm{C})$ rats}

Induction of renal hypertension was carried out in rats according to the $1 \mathrm{~K}-1 \mathrm{C}$ rat model originally described by Goldblatt et al. [35] and later modified by Laffan et al. [36] and McCaa et al. [37]. Briefly, male Wistar rats (3 months old, weighing 200-250 g) were used for induction of the $1 \mathrm{~K}-1 \mathrm{C}$ model. The rats were anesthetized with intramuscular injection of ketamine $(40 \mathrm{mg} /$ $\mathrm{kg})$, xylazine $(8 \mathrm{mg} / \mathrm{kg})$ and chlorpromazine $(4 \mathrm{mg} /$ $\mathrm{kg})$. The renal artery was exposed through a laparotomy and dissected from the renal vein. A U-shaped silver clip with an internal diameter of $0.20 \mathrm{~mm}$ was placed around the left renal artery as close as possible to the aorta. The clip was then turned such that the slit opening faced the abdomen, and the contralateral kidney was removed without the adrenal gland (Goldblatt rats). Sham operation for the control for the $1 \mathrm{~K}-1 \mathrm{C}$ model was performed in a similar manner, including the removal of one kidney but not the clipping of the remaining renal artery ( $1 \mathrm{~K}-\mathrm{NC})$. Surgical mortality was below 5\%, and the 5-week mortality rate was $15 \%$. Three weeks after the surgical operation, $1 \mathrm{~K}-1 \mathrm{C}$ rats were used for blood pressure monitoring after confirming the presence of high blood pressure (systolic blood pressure $>160 \mathrm{mmHg}$ ) using a tail-cuff method. Then, the rats were randomly divided into five groups: a control group ( $2 \mathrm{~K}-\mathrm{NC}, n=7)$; a sham-operated group ( $1 \mathrm{~K}-\mathrm{NC}, n=7)$; a $1 \mathrm{~K}-1 \mathrm{C}$ group $(n=7)$, a $1 \mathrm{~K}-1 \mathrm{C}+\mathrm{HDR}-2(150 \mathrm{mg} / \mathrm{kg} /$ day by oral gavage $)$ group $(n=7)$, a $1 \mathrm{~K}-1 \mathrm{C}+\mathrm{HDR}-2(300 \mathrm{mg} / \mathrm{kg} /$ day by oral gavage) group $(n=7)$, and a $1 \mathrm{~K}-1 \mathrm{C}+$ mixture of $\mathrm{L}_{\text {-arginine }}$ and GABA (4:6 ratio; $10 \mathrm{mg} / \mathrm{kg} /$ day by oral gavage) group $(n=7)$. HDR-2 was dissolved in saline, and the control group received only saline. Then, the dosing volume was calculated from the body weight of rats (0.5 mL per rat).

\section{Experimental groups}

Five WKY and twenty SHR were randomly assigned to five groups $(n=5)$ : a control WKY group and a control SHR group, both of which received water as vehicle, and SHR groups treated with HDR-2 (150 or $300 \mathrm{mg}$ / $\mathrm{kg} /$ day by oral gavage) or a mixture of $\mathrm{L}^{\text {-arginine and }}$ GABA (4:6 ratio; $10 \mathrm{mg} / \mathrm{kg} /$ day by oral gavage) for 5 weeks. HDR-2 was dissolved in saline, and the control group received only saline. Then, the dosing volume was calculated from the body weight of rats $(0.5 \mathrm{~mL}$ per rat). HDR-2 treatment was stopped $24 \mathrm{~h}$ before the end of the experiment to study the long-term effects of HDR-2 without involving the effects of acute administration. Food and water intake were recorded daily for all groups. During the experimental periods, rats had free access to tap water and chow. The body weight was measured every week.

\section{Tissue collection and cardiac and renal weight indices}

When the experimental period was complete, animals were fasted for $18 \mathrm{~h}$ and anesthetized with $2.5 \mathrm{~mL} /$ kg pentobarbital (intraperitoneal injection; i.p.), followed by decapitation (with rats held horizontally during blood collection to minimize contamination of the blood sample by gastric juice). The kidneys and ventricles were then removed and weighed. The heart was divided into the right ventricle and left ventricle plus septum. The heart weight index, kidney weight index, liver weight index and spleen weight index were calculated by dividing the heart weight, kidney weight, liver weight and spleen weight by the body weight (BW). The thoracic aorta and lungs were excised for further analyses and stored at $-80^{\circ} \mathrm{C}$ until analysis. The thoracic aortae were isolated immediately and used for ex vivo vascular function studies.

\section{Measurement of systolic blood pressure and heart rate in unanesthetized rats}

The average systolic blood pressure of the animals was measured by the tail-cuff method using a noninvasive blood pressure system (NIBP system, Panlab/Harvard Apparatus, Barcelona, Spain) before all treatments and every subsequent week after the treatment started. Briefly, all animals were acclimated to the restraint condition before measurement. They were immobilized in a prewarmed chamber $\left(28-30^{\circ} \mathrm{C}\right)$ for at least $30 \mathrm{~min}$ before each blood pressure measurement was carried out. At least six to seven successive measurements were recorded, and the average values of these readings are reported. All SBP measurements were carried out at the same time of day. 


\section{Ex vivo experiments for measurement of vascular responsiveness}

After anesthesia with isoflurane, S-D rat or SHR thoracic aortae were resected and placed in Krebs' buffer solution bubbled with $5 \% \mathrm{CO}_{2}$ and $95 \% \mathrm{O}_{2}$. The contractile activity was measured according to the same method as in our former study [24]. Upon attaining a constriction plateau, vasodilation ability was verified by treatment with acetylcholine chloride (ACh, $10^{-9}-10^{-3} \mathrm{M}$ ) or sodium nitroprusside (SNP, $\left.10^{-9}-10^{-3} \mathrm{M}\right)$ in the endothelium-denuded rings.

\section{Cell preparation}

Cultured hippocampal neurons were proceeded in the same manner as described in previous study [24]. Murine RAW 264.7 macrophages (40071) were obtained from the Korea Cell Line Bank (KCLB, Seoul, Korea) and human umbilical vein endothelial cells (HUVECs) were obtained from the American Type Culture Collection (ATCC, Manassas, VA, USA). iNOS and eNOS were also measured in the same method as in our former study [24].

\section{Gene expression analysis}

Gene expression in cultured cells was analyzed by RTPCR, as previously described [24]. The specific primers used in this study (eNOS, nNOS, and iNOS) were also analyzed using the same primers used in our previous study [24].

\section{NO production assay}

The total $\mathrm{NO}$ (nitrite; $\mathrm{NO}_{2}{ }^{-}$and nitrate; $\mathrm{NO}_{3}{ }^{-}$) levels in cell culture supernatants and serum were determined using the Griess reaction. Cell culture supernatants were collected $3 \mathrm{~h}$ after treatment with different compounds. Blood samples were collected at the end of the experiment from all rats by cardiac puncture. The plasma samples $(100 \mu \mathrm{L})$ were mixed with zinc sulfate $(50 \mu \mathrm{L}$, final concentration $15 \mathrm{mg} / \mathrm{mL})$ and then centrifuged at $1000 \times \mathrm{g}$ for $10 \mathrm{~min}$. The supernatant $(100 \mu \mathrm{L})$ was mixed with vanadium (III) chloride $(100 \mu \mathrm{L}$, final concentration $8 \mathrm{mg} / \mathrm{mL}$ ) and added to $2 \%$ sulfanilamide in $5 \% \mathrm{H}_{3} \mathrm{PO}_{4}$ solution $(50 \mu \mathrm{L})$ and $0.1 \% N$-(1-naphthyl) ethylenediamine $(50 \mu \mathrm{L})$. After incubation at $37^{\circ} \mathrm{C}$ for $30 \mathrm{~min}$, the absorbance was measured at $540 \mathrm{~nm}$. The measurements were performed in triplicate, and the NO concentration $(\mu \mathrm{M})$ was expressed as the means \pm standard deviation (SD).

\section{Determination of plasma and lung ACE activity}

ACE activity in serum and lung tissue was measured by using N-Hippuryl-His-Leu (HHL) as a substrate. The serum samples $(50 \mu \mathrm{L})$ were mixed with $0.1 \mathrm{M}$ sodium borate buffer $(\mathrm{pH} 8.3,100 \mu \mathrm{L})$ containing $300 \mathrm{mM} \mathrm{NaCl}$ and $5 \mathrm{mM}$ HHL $(50 \mu \mathrm{L})$. The mixture was incubated at $37^{\circ} \mathrm{C}$ for $45 \mathrm{~min}$, and then the enzymatic reaction was stopped with the addition of $2 \mathrm{~N} \mathrm{HCl}$ solution $(200 \mu \mathrm{L})$. The reaction mixture was separated with ethyl acetate $(2 \mathrm{~mL})$. The upper ethyl acetate layer $(1.5 \mathrm{~mL})$ was concentrated and dissolved with $1 \mathrm{M} \mathrm{NaCl}$ solution $(1 \mathrm{~mL})$. The absorbance was measured at $228 \mathrm{~nm}$, and the hippuric acid content in the serum and lung was calculated using a calibration curve of the hippuric acid standard.

\section{Determination of serum angiotensin II content}

Plasma concentrations of angiotensin II (AngII) were quantified by an ELISA kit (AngII ELISA, Cayman, Ann Arbor, MI, USA) based on the manufacturer's instructions. The plasma sample was added to a plate coated with AngII antibody, and then, biotinylated AngII solution was directly added to the plate, which was incubated for $2 \mathrm{~h}$. The plate was washed with wash buffer, the buffer was removed, and the resulting contents were incubated with streptavidin peroxidase conjugate for $50 \mathrm{~min}$ at room temperature. After adding chromogen substrate, the plate was incubated for $10 \mathrm{~min}$, and the absorbance was read at $450 \mathrm{~nm}$.

\section{Protein extraction and immunoblot assays}

Samples of aorta tissue were washed three times with cold PBS before being lysed in RIPA lysis buffer $(10 \mathrm{mmol} / \mathrm{L}$ Tris- $\mathrm{HCl}, \mathrm{pH} 7.5 ; 1 \% \mathrm{NP}-40 ; 0.1 \%$ sodium deoxycholate; $0.1 \% \mathrm{SDS} ; 150 \mathrm{mmol} / \mathrm{L} \mathrm{NaCl}$; and $1 \mathrm{mmol} / \mathrm{L}$ EDTA) supplemented with $1 \times$ protease and phosphatase inhibitor cocktail (Thermo, Fremont, CA, USA) on ice. The separated proteins were transferred onto a nitrocellulose membrane. The anti-eNOS (1:100), anti-phospho-eNOS $\left(1: 100\right.$, Ser $\left.^{1177}\right)$ and anti- $\beta$-actin (1:3000) antibodies and secondary antibodies (1:10000) were obtained from Cell Signaling Technology (Beverly, MA, USA). Immunoreactive protein bands were visualized using a ChemiDoc XRS+ System (Bio-Rad) and quantified with Gel Pro Analyzer software (Silk Scientific, Inc., Orem, UT, USA). The internal control, $\beta$-actin, was used to normalize differences due to loading variations.

\section{Statistical analysis}

Results are presented as the mean and standard error of the mean (SEM) or standard deviation (SD). Data were analyzed by Student's t-test or two-way analysis of variance (ANOVA) with GraphPad Prism version 8.0.0 for Windows (GraphPad, Inc., San Diego, California, USA) software programs. Differences at the $p<0.05$ level were considered statistically significant. 


\section{Results}

\section{Effects of HDR-2 on isolated rat aortic rings precontracted} with PHE

In our previous study, 5-uRCK exhibited an endothelium-dependent vasodilator effect, while $D P$ induced a partial endothelium-dependent vasodilator effect. Additionally, we showed that $\mathrm{Hy}-D P$ has a stronger effect than $D P$ and that Hy-DP improves impaired endotheliumdependent vasorelaxation in the aorta in SD rats [24]. In particular, the most significant effect was observed when Hy-DP and 5-uRCK were mixed at a 2:1 ratio (HDR-2). As shown in Fig. 1a and b, HDR-2 significantly relaxed endothelium-intact aortic rings precontracted with PHE $(10 \mu \mathrm{M})$. As shown in Fig. 1c, HDR-2-induced relaxation was significantly inhibited by pretreatment with $\mathrm{N}^{\omega}$-nitro- ${ }_{\mathrm{L}}$-arginine methyl ester $\left({ }_{\mathrm{L}}-\mathrm{NAME}, 10 \mu \mathrm{M}\right)$ and $1 \mathrm{H}$-[1,2,4] oxadiazolo[4,3-a]quinoxalin-1-one (ODQ, $10 \mu \mathrm{M})$ in rat aortic rings with intact endothelia. However, the use of ${ }_{\mathrm{L}}$-NAME and ODQ did not completely inhibit HDR-2-induced relaxation. A comparison of the vasodilatory effect between the intact $(+E)$ and denuded $(-E)$ epithelia groups showed that the vasodilatory effect induced by $D P$ were significantly inhibited in the -E group (Fig. 1d). However, in the $-E$ group, the inhibitory effect of Hy-DP treatment $(36.69 \pm 4.82 \%)$ was greater than the effect of $D P$ treatment $(17.55 \pm 7.01 \%$ ) (Fig. $1 \mathrm{~d}$ and e). HDR-2-induced relaxation in rat aortic preparations was more significantly inhibited $(55.77 \pm 7.88 \%)$ than Hy-DP-induced relaxation by denudation of the endothelial layer. Interestingly, the relaxation induced by $5-u \mathrm{RCK}$ was completely abolished in denuded aortic rings. These results indicated that HDR-2 exhibited a partial endothelium-dependent vasodilator effect.

\section{Effects of HDR-2 on NOS gene expression}

As shown in Fig. 2a, iNOS mRNA was strongly expressed in lipopolysaccharide (LPS; from Escherichia coli 0111:B4)-stimulated RAW 264.7 cells. However, iNOS mRNA levels were not increased by treatment with HDR2. In the expression of nNOS, as shown in Fig. 2b, nNOS mRNA was significantly increased by glutamate treatment in cultured hippocampal neurons, whereas HDR-2 treatment did not affect the expression of nNOS mRNA. We investigated the effects of HDR-2 on eNOS mRNA expression in HUVECs and verified that eNOS mRNA levels were significantly increased by HDR-2 treatment (Fig. 2c). We reconfirmed eNOS mRNA expression by real-time qPCR (Fig. 2d) and verified that the eNOS mRNA level of HUVECs was significantly increased in both ACh-treated cells and HDR-2 treated cells.

\section{HDR-2 stimulates the production of NO}

To elucidate the relationship between the amount of NO production according to the eNOS expression effect of
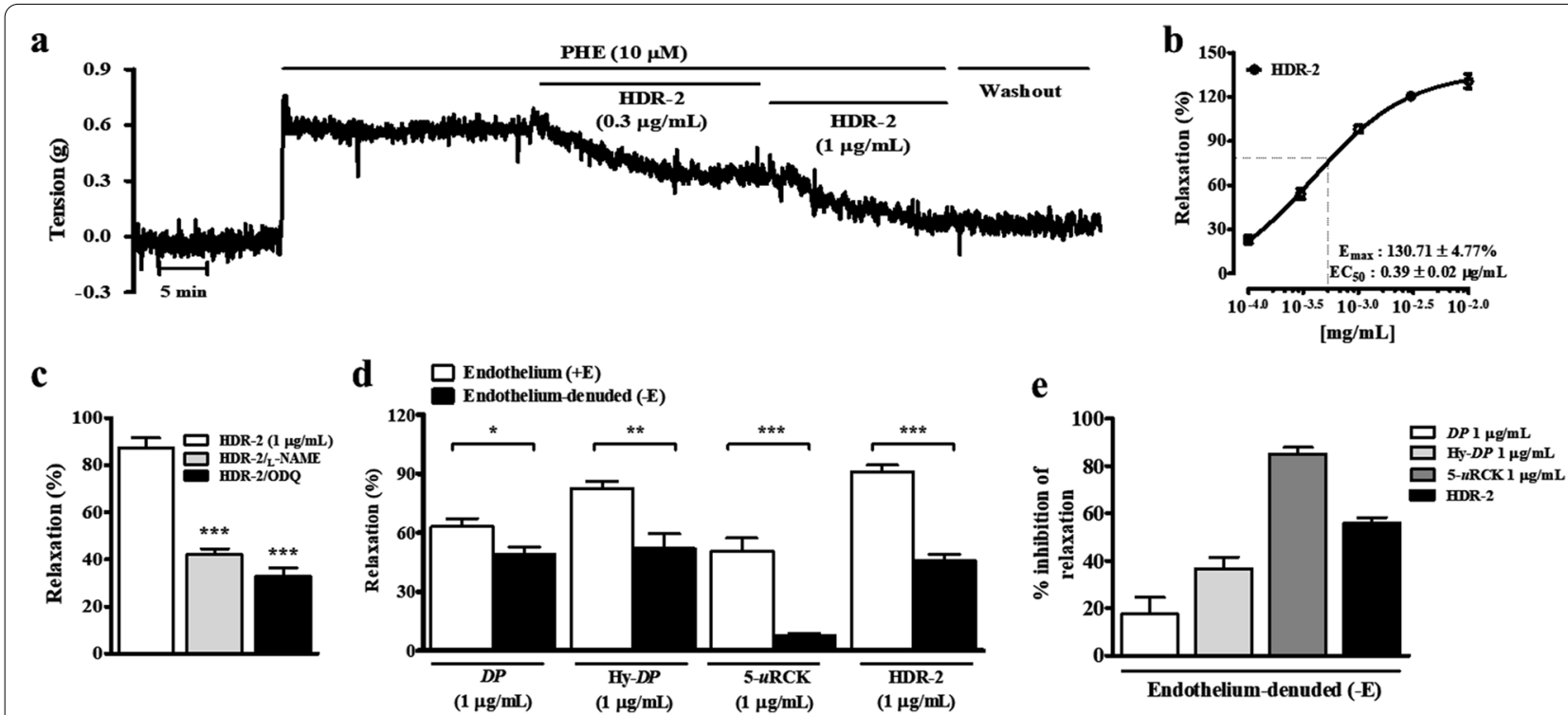

Fig. 1 Effects of HDR-2 on thoracic aorta function. Representative traces of vascular relaxant responses induced by HDR-2 (a) in rat thoracic aortae precontracted with $10 \mu \mathrm{M}$ PHE. Percent relaxation in response to increasing concentrations of HDR-2 (b) in aortic rings from SD rats. Lack of effect of L-NAME and ODQ on rat thoracic aorta relaxation induced by HDR-2 (c). Vasorelaxant effects of DP, Hy-DP, 5-URCK and HDR-2 in thoracic aortae with denuded endothelia ( $-E)$ and intact endothelia (+E) (d). Inhibition of the vasorelaxant effects of DP, Hy-DP, 5-uRCK and HDR-2 in endothelium-free thoracic aortae precontracted with $10 \mu \mathrm{M}$ PHE (e). The relaxation (\%) values (mean \pm SEM) are relative to the basal (submaximal) relaxation levels measured before PHE treatment, which were taken to be $100 \% .{ }^{*} P<0.05,{ }^{* *} P<0.01$ and ${ }^{* * *} P<0.001$ vs the CTL group 


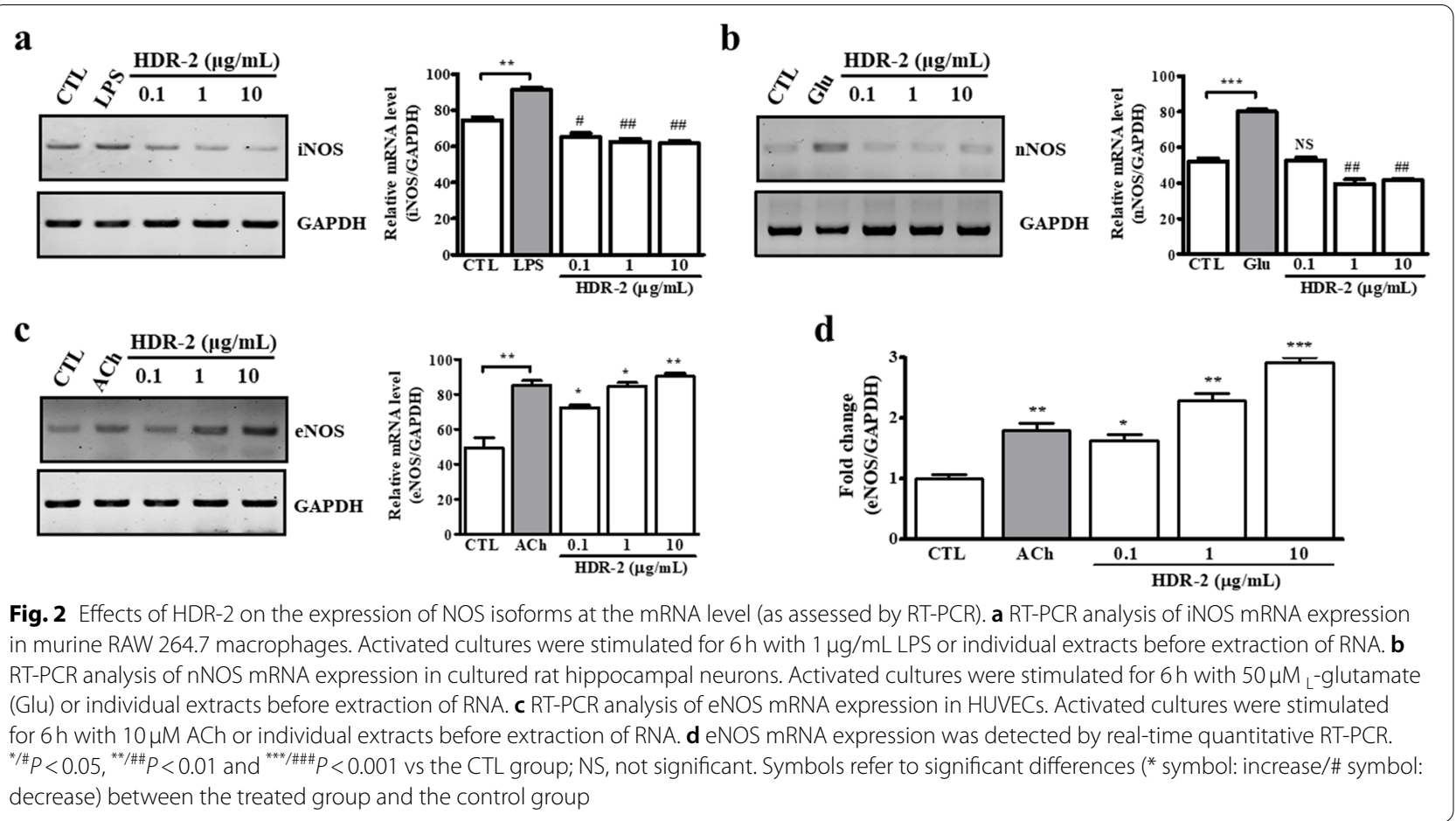

HDR-2, we verified the amount of NO produced in RAW 264.7 macrophages, cultured hippocampal neurons and HUVECs (Fig. 3). NO production was not changed by HDR-2 in cultured hippocampal neurons and RAW 264.7 macrophages, like the expression level of eNOS, but rather, NO production decreased as the concentration of HDR-2 increased. However, as shown in Fig. 3c, NO release was increased in a dose-dependent manner after HDR-2 treatment HUVECs, which may be related to the increased mRNA expression level of eNOS in HUVECs.

\section{HDR-2 decreased systolic blood pressure in $1 \mathrm{~K}-1 \mathrm{C}$ rats}

For the practical purpose of the utilization of HDR-2 as a physiological modulator, its antihypertensive activity was evaluated in vivo by measuring the variation in the SBP of $1 \mathrm{~K}-1 \mathrm{C}$ hypertensive rats over long-term intragastric administration (Fig. 4) and with an acute administration test (Fig. 5). Figure 4 shows the SBP change in all tested groups during the long-term intragastric administration experiment. The changes in the mean SBP of the $1 \mathrm{~K}-1 \mathrm{C}$ rats treated with HDR-2 for 2 weeks were measured using a tail-cuff method. The SBP values in the $1 \mathrm{~K}-1 \mathrm{C}$ group $(214.67 \pm 5.55 \mathrm{mmHg}), 1 \mathrm{~K}-1 \mathrm{C} /$ HDR-2 groups $(150 \mathrm{mg} / \mathrm{kg} ; 186.71 \pm 7.34 \mathrm{mmHg}, 300 \mathrm{mg} /$ $\mathrm{kg} ; \quad 173.14 \pm 6.64 \mathrm{mmHg})$ and $1 \mathrm{~K}-1 \mathrm{C} / \mathrm{Arg}+\mathrm{GABA}$ group $(186.16 \pm 13.47 \mathrm{mmHg})$ were significantly higher than that of the sham-operated group $(1 \mathrm{~K}-\mathrm{NC}$, $146.33 \pm 10.27 \mathrm{mmHg}$ ) (Fig. 4a). However, the SBP values in the $1 \mathrm{~K}-1 \mathrm{C} / \mathrm{HDR}-2$ groups and $1 \mathrm{~K}-1 \mathrm{C} / \mathrm{Arg}+\mathrm{GABA}$ group at week two were significantly lower than those in the $1 \mathrm{~K}-1 \mathrm{C}$ group. The data were expressed as $\triangle \mathrm{SBP}$, which was the difference between the SBP on day 0 and the SBP measured one or 2 weeks after the beginning of the experiment. As shown in Fig. $4 \mathrm{~b}$, the $\triangle \mathrm{SBP}$ values in the $1 \mathrm{~K}-1 \mathrm{C}$-control group at weeks $1(23.67 \pm 3.78 \mathrm{mmHg})$ and $2(29.50 \pm 2.42 \mathrm{mmHg})$ were significantly higher $(P<0.01)$ than those in the sham-operated group (1 K-NC). The HDR-2-treated groups exhibited significant decreases in the mean $\triangle \mathrm{SBP}$ observed in the $1 \mathrm{~K}-1 \mathrm{C}$ rats but did not demonstrate a change in heart rate compared with normotensive $1 \mathrm{~K}-\mathrm{NC}$ rats and $1 \mathrm{~K}-1 \mathrm{C}$ rats (Table 1 ). The $\triangle \mathrm{SBP}$ of the rats administered HDR-2 $(300 \mathrm{mg} / \mathrm{kg})$ was similar to that of rats on grouping day (0 day) until 1 week. After 2 weeks of treatment, the $\triangle \mathrm{SBP}$ level of the HDR-2 $(300 \mathrm{mg} / \mathrm{kg})$ group was $8.14 \pm 0.85 \mathrm{mmHg}(P>0.05, \mathrm{NS})$, which was lower than that of the 0 -day rats (Fig. $4 \mathrm{~b}$ ). Moreover, $1 \mathrm{~K}-1 \mathrm{C}$ rats treated with the combination of ${ }_{L}$-arginine and GABA also exhibited a significant decrease in SBP compared to the $1 \mathrm{~K}-\mathrm{NC}$ rats $(P<0.01)$ or $2 \mathrm{~K}-\mathrm{NC}$ rats.

\section{Antihypertensive action of single oral administration of HDR-2 in $1 \mathrm{~K}-1 \mathrm{C}$ rats}

In the short-term test, the antihypertensive activity of HDR-2 was evaluated by measuring the SBP in $1 \mathrm{~K}-1 \mathrm{C}$ rats at $0,0.5,1,1.5,2,2.5$ and $3 \mathrm{~h}$ after oral 
a

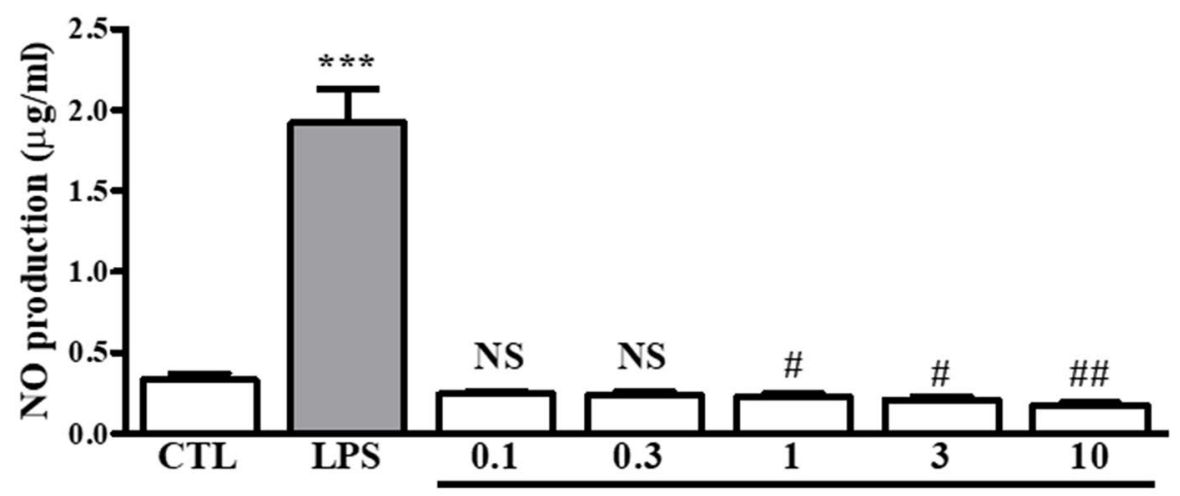

b

HDR-2 $(\mu \mathrm{g} / \mathrm{mL})$

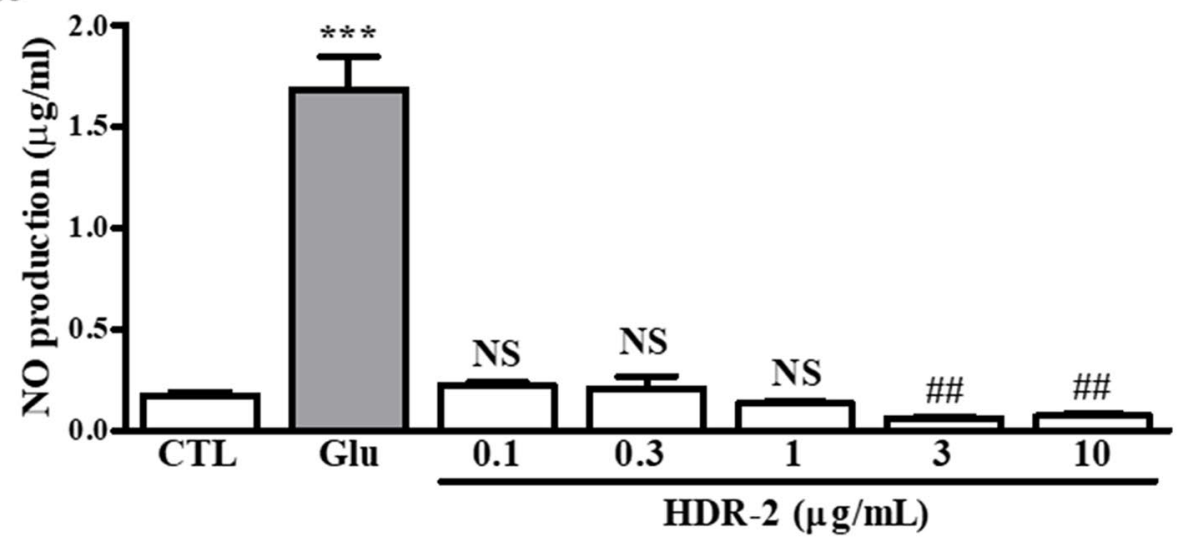

C

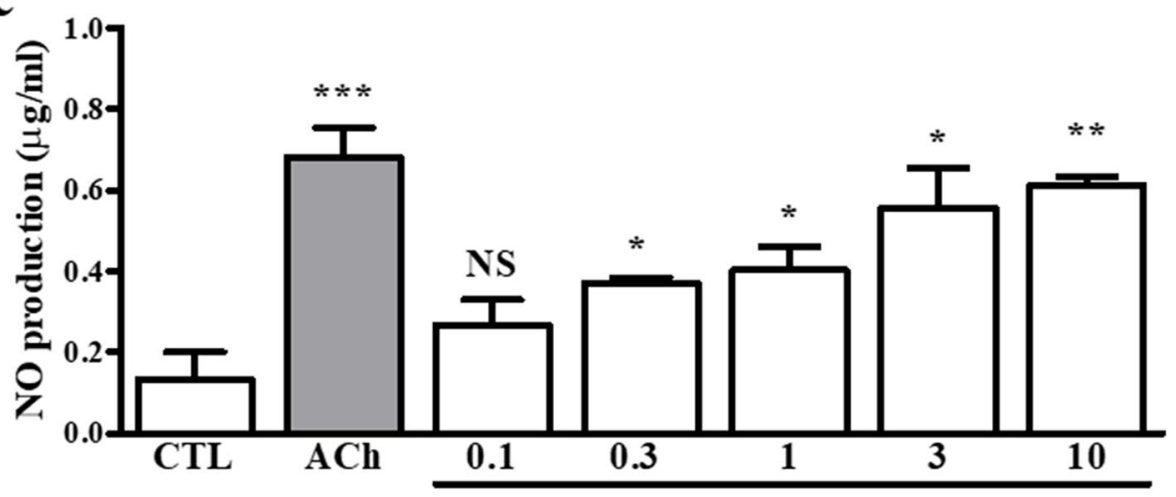

HDR-2 $(\mu \mathrm{g} / \mathrm{mL})$

Fig. 3 Effects of HDR-2 on NO levels. NO levels in murine RAW 264.7 macrophages, hippocampal neurons, and HUVECs treated with HDR-2. NO production at baseline (control; CTL) and after treatment with $1 \mu \mathrm{g} / \mathrm{mL}$ LPS or individual extracts in murine RAW 264.7 macrophages (a), at baseline and after treatment with $50 \mu \mathrm{M}$ Glu or individual extracts in cultured rat hippocampal neurons (b), and at baseline and after treatment with $10 \mu \mathrm{M}$ ACh or individual extracts in HUVECs $(\mathbf{c}) .{ }^{* \# \#} P<0.05,{ }^{* * / \# \#} P<0.01$ and ${ }^{* * * \# \# \#} P<0.001$ vs the CTL group; symbols refer to significant differences ${ }^{*}$ symbol: increase/\# symbol: decrease) between the treated group and the control group. NS, not significant

administration, as shown in Fig. 5. Administration of saline to $1 \mathrm{~K}-1 \mathrm{C}$ rats caused no changes in SBP recorded from $0 \mathrm{~h}$ to $3 \mathrm{~h}$ following treatment. By contrast, half an hour after administration of HDR-2 (150 and $300 \mathrm{mg} / \mathrm{kg}$

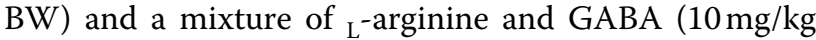
$B W)$, the blood pressures of the three groups had undergone a slight decrease. As shown in Fig. 5b, the maximum decline exhibited by the three groups was observed at $3 \mathrm{~h}$, 

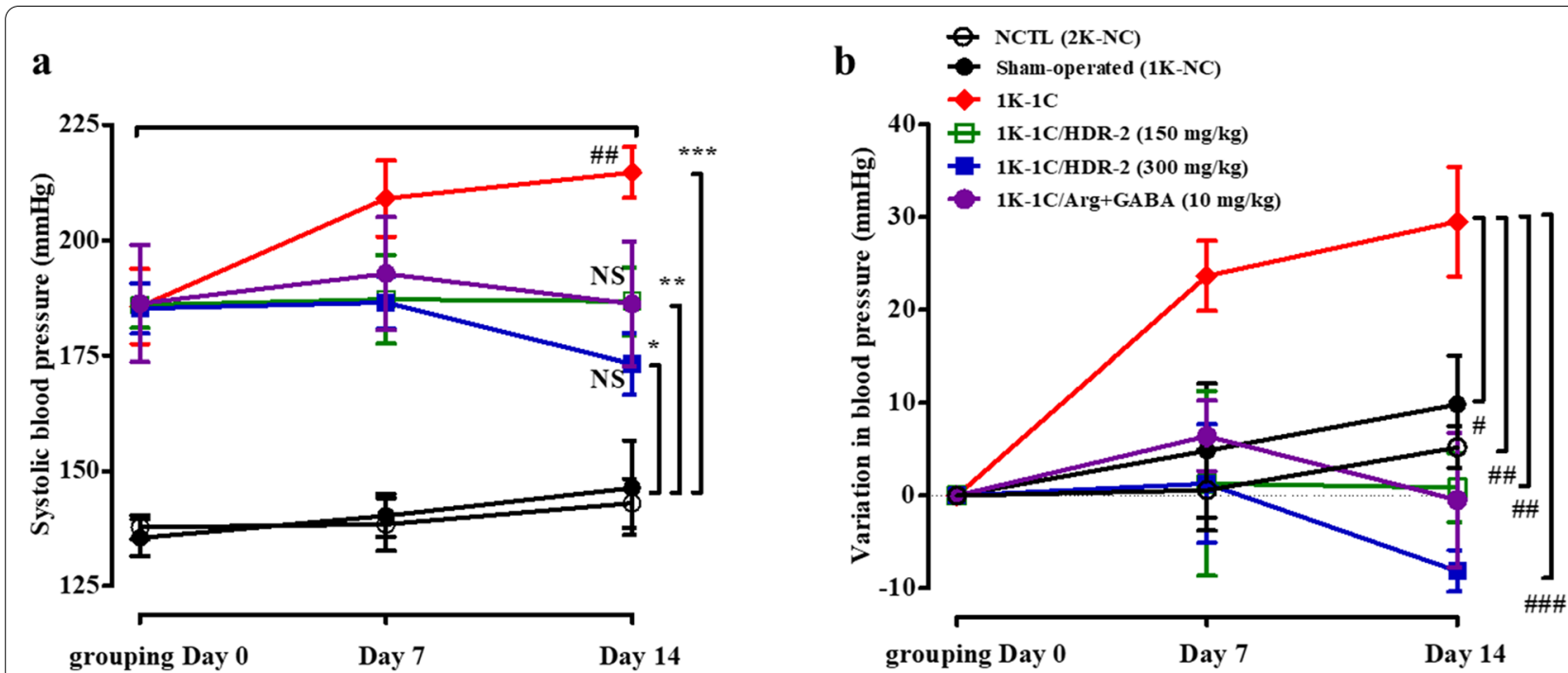

Fig. 4 Effect of HDR-2 on systolic blood pressure (SBP) in $1 \mathrm{~K}-1 \mathrm{C}$ hypertensive rats at 0-2 weeks. Rats were intragastrically treated with saline,

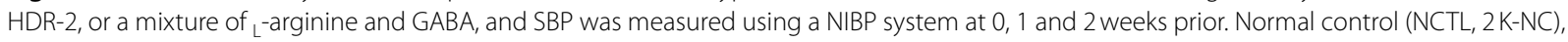
sham-operated control $(1 \mathrm{~K}-\mathrm{NC})$ and $1 \mathrm{~K}-1 \mathrm{C}$ control: rats were treated with saline. $1 \mathrm{~K}-1 \mathrm{C} / \mathrm{HDR}-2: 1 \mathrm{~K}-1 \mathrm{C}$ rats were treated with $\mathrm{HDR}-2150 \mathrm{mg} / \mathrm{kg}$ BW or $300 \mathrm{mg} / \mathrm{kg}$ BW. $1 \mathrm{~K}-1 \mathrm{C} / \mathrm{Arg}+$ GABA: $1 \mathrm{~K}-1 \mathrm{C}$ rats were treated with L-arginine $(4 \mathrm{mg} / \mathrm{kg} \mathrm{BW})$ and GABA $(6 \mathrm{mg} / \mathrm{kg}$ BW). Seven rats $(n=7)$ were included in each group. Values are expressed as the mean \pm SD. ${ }^{*},{ }^{* *}$ and ${ }^{* * *}$ indicate $P<0.05, P<0.01$ and $P<0.001$, respectively, compared with the sham-operated control (1 K-NC), \#, \#\# and \#\#\# indicate $P<0.05, P<0.01$ and $P<0.001$, respectively, compared with the $1 \mathrm{~K}-1 \mathrm{C}$ control group

and the decreases in SBP were $14.50 \pm 1.51 \mathrm{mmHg}$ (HDR$2,150 \mathrm{mg} / \mathrm{kg}), 22.75 \pm 3.06 \mathrm{mmHg}(\mathrm{HDR}-2,300 \mathrm{mg} / \mathrm{kg})$ and $17.0 \pm 2.62 \mathrm{mmHg}$ (Arg + GABA, $10 \mathrm{mg} / \mathrm{kg})$. SBP returned to the untreated initial levels within $24 \mathrm{~h}$ post administration (data not shown).

Kidney and heart weight of $1 \mathrm{~K}-1 \mathrm{C}$ hypertensive rat models Kidney and heart weights are shown in Table 1. The left kidney weights of the $1 \mathrm{~K}-1 \mathrm{C}$ group were significantly heavier than those of the control group ( $2 \mathrm{~K}-\mathrm{NC}$ ) and sham-operated group (1K-NC). During the 2-week HDR-2 treatment, $150 \mathrm{mg} / \mathrm{kg}$ and $300 \mathrm{mg} / \mathrm{kg}$ treatment significantly reduced the increase in kidney weight in $1 \mathrm{~K}-1 \mathrm{C}$ rats. There were no differences in heart weight or heart index among all groups. Furthermore, all groups had similar heart rates.

\section{HDR-2 decreased ACE, Angll and NO levels in $1 \mathrm{~K}-1 \mathrm{C}$ rats in a long-term experiment}

To further investigate the mechanism underlying the ACE inhibition activities of HDR-2 in $1 \mathrm{~K}-1 \mathrm{C}$ rats, the plasma and lung tissue ACE activities and the related plasma AngII levels were determined, and the results are presented in Fig. 6. The HDR-2 (150 mg/kg)- and HDR-2 $(300 \mathrm{mg} / \mathrm{kg})$-treated groups exhibited significantly lower ACE activities in the plasma and lung tissue than the $1 \mathrm{~K}-1 \mathrm{C}$ rats (Fig. 6a, b). However, significant differences in the ACE activities between the $150 \mathrm{mg} / \mathrm{kg}$ and $300 \mathrm{mg} /$ $\mathrm{kg}$ treated groups were not observed $(P>0.05)$. Moreover, the beneficial effect of HDR-2 in relieving hypertension was also evidenced by the reduction in AngII concentrations in plasma samples (Fig. 6c). Compared with control $1 \mathrm{~K}-1 \mathrm{C}$ rats, HDR-2-treated $1 \mathrm{~K}-1 \mathrm{C}$ rats demonstrated significantly reduced plasma AngII levels at 2 weeks after treatment $(P<0.001)$. The concentrations of AngII in $1 \mathrm{~K}-1 \mathrm{C}$ rat plasma samples were also significantly decreased in $1 \mathrm{~K}-1 \mathrm{C}$ rats treated with ${ }_{\mathrm{L}}$-arginine and GABA $(P<0.001)$. As shown in Fig. $6 \mathrm{~d}$, the serum NO level was increased in the $1 \mathrm{~K}-1 \mathrm{C}$ hypertensive rat models. Treatment with HDR-2 (150 and $300 \mathrm{mg} / \mathrm{kg}$ ) significantly decreased the generation of NO in serum compared to the $1 \mathrm{~K}-1 \mathrm{C}$ hypertensive control condition.

\section{HDR-2 decreased systolic blood pressure in SHR rats}

The pathogenesis of hypertension in SHRs is similar to that in human essential hypertension [38]. Figure 7 shows the effect of the HDR-2 treatment, administered for 5 weeks, on SBP and heart rate in SHRs. Briefly, there were no significant differences among SHR groups at the beginning of the experiment, indicating that the baseline blood pressure of different SHR groups was the same. The SBP values in the SHR group $(235.80 \pm 10.59 \mathrm{mmHg})$, SHR/HDR-2 groups $(150 \mathrm{mg} / \mathrm{kg} ; 198.0 \pm 11.79 \mathrm{mmHg}$, $300 \mathrm{mg} / \mathrm{kg} ; 189.6 \pm 12.58 \mathrm{mmHg})$ and SHR/Arg + GABA group $(193.8 \pm 11.39 \mathrm{mmHg})$ at week 12 were significantly higher than that of the normotensive WKY group 
$\mathbf{a}$

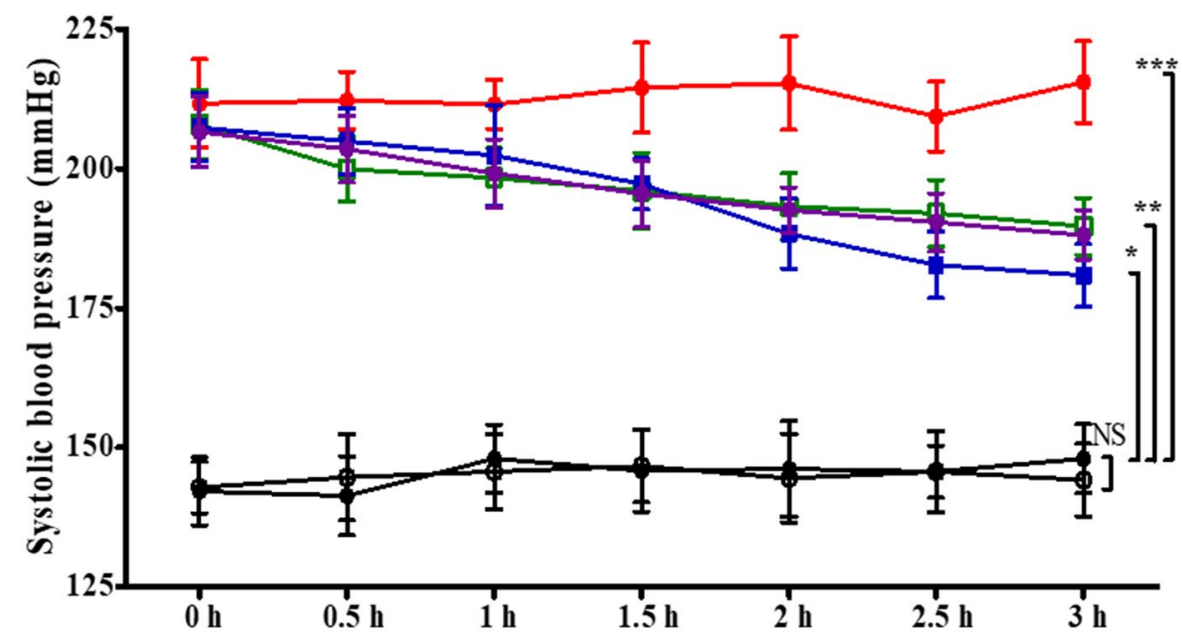

b

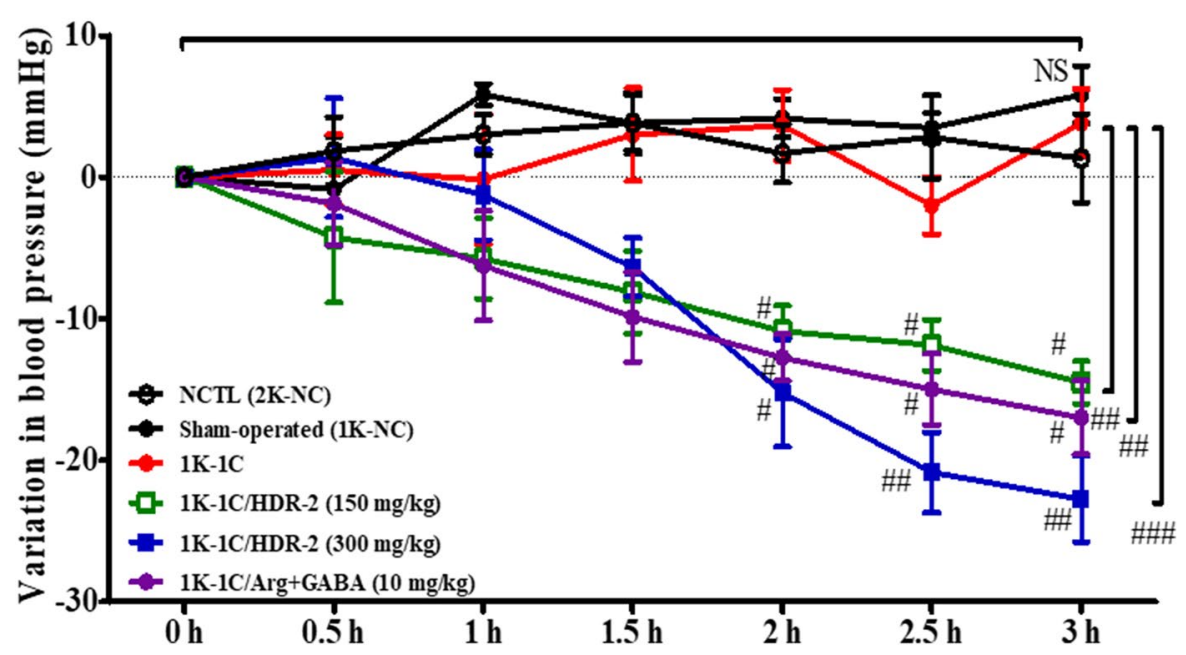

Fig. 5 Acute effects of HDR-2 on changes in systolic blood pressure (SBP) in $1 \mathrm{~K}-1 \mathrm{C}$ hypertensive rat models. a Antihypertensive effects of different doses of HDR- 2 in $1 \mathrm{~K}-1 \mathrm{C}$ rats within $3 \mathrm{~h}$ of administration with a single oral dose. $\mathbf{b}$ The decreasing amplitude of SBP of $1 \mathrm{~K}-1 \mathrm{C}$ rats at different time points after a single oral dose. Values are expressed as the mean \pm SD. ${ }^{* * *}$ and ${ }^{* * *}$ indicate $P<0.05, P<0.01$ and $P<0.001$, respectively, compared with the sham-operated control ( $1 \mathrm{~K}-\mathrm{NC})$, \#, \#\# and \#\#\# indicate $P<0.05, P<0.01$ and $P<0.001$, respectively, compared with the $1 \mathrm{~K}-1 \mathrm{C}$ control group

Table 1 Kidney and heart weights and heart rates of $1 \mathrm{~K}-1 \mathrm{C}$ hypertensive rats over two weeks. Data are expressed as the mean \pm SD

\begin{tabular}{lllllll}
\hline Group & Number & $\begin{array}{l}\text { Right kidney } \\
\text { weight } \mathbf{( m g )}\end{array}$ & Left kidney weight $\mathbf{( m g )}$ & Heart weight(mg) & Heart index (mg/g) & $\begin{array}{l}\text { Heart rate } \\
\mathbf{( b p m )}\end{array}$ \\
\hline Control (2 K-NC) & $n=7$ & $1291.4 \pm 9.4$ & $1266.4 \pm 26.4$ & $1196.0 \pm 42.4$ & $3.8 \pm 0.1$ & $395.7 \pm 30.8$ \\
Sham-operated control (1 K-NC) & $n=7$ & $1331.6 \pm 46.3$ & $1285.2 \pm 44.3$ & $1380.6 \pm 80.1$ & $3.9 \pm 0.1$ & $379.5 \pm 24.2$ \\
$\mathbf{1}$ K-1C & $n=7$ & - & $1626.3 \pm 158.4$ & $1299.6 \pm 82.5$ & $3.9 \pm 0.2$ & $380.8 \pm 23.9$ \\
$\mathbf{1}$ K-1C/HDR-2 (150 $\mathbf{~ m g / k g ) ~}$ & $n=7$ & - & $1422.2 \pm 140.3$ & $1149.2 \pm 33.7$ & $4.0 \pm 0.3$ & $381.4 \pm 15.8$ \\
$\mathbf{1}$ K-1C/HDR-2 (300 $\mathbf{~ m g / k g ) ~}$ & $n=7$ & - & $1455.7 \pm 43.4$ & $1282.6 \pm 49.9$ & $4.0 \pm 0.1$ & $377.3 \pm 20.3$ \\
$\mathbf{1}$ K-1C/Arg+GABA (10 mg/kg) & $n=7$ & - & $1280.8 \pm 132.2$ & $1162.8 \pm 135.1$ & $4.1 \pm 0.3$ & $373.1 \pm 26.3$ \\
\hline
\end{tabular}



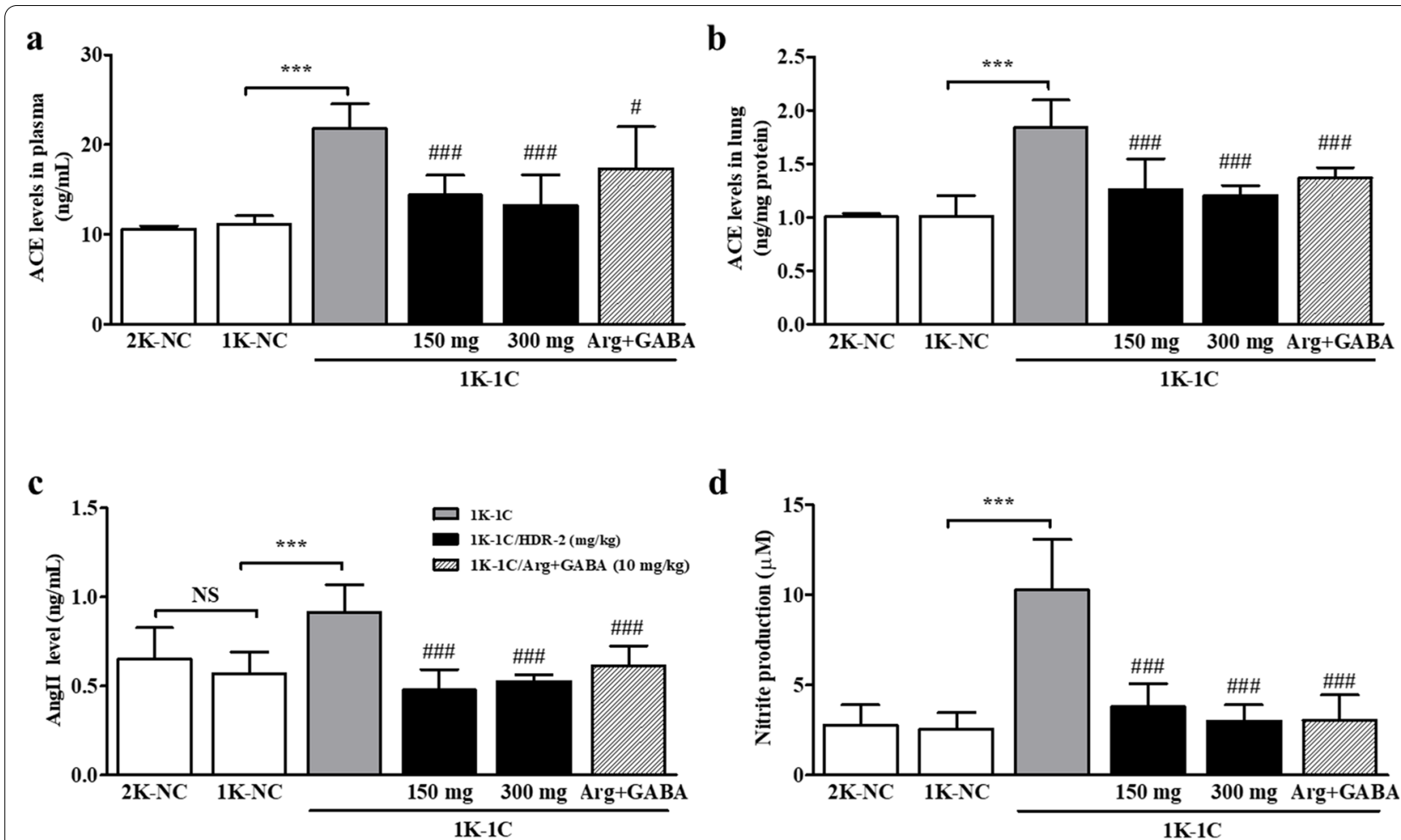

d

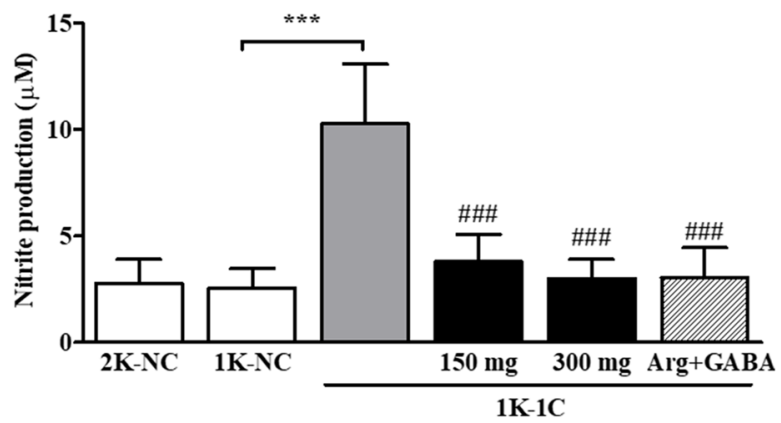

Fig. 6 a Plasma ACE levels in the indicated treatment groups. $\mathbf{b}$ Lung ACE levels in the indicated treatment groups. $\mathbf{c}$ Plasma Angll levels in the indicated treatment groups. $\mathbf{d}$ Plasma nitric oxide $(\mathrm{NO})$ levels in the indicated treatment groups. The values represent the means $\pm S D ;{ }^{* * *} P<0.001$, compared with the sham-operated control ( $1 \mathrm{~K}-\mathrm{NC}$ ) group; ${ }^{\prime} P<0.05$, ${ }^{\# \#} P<0.01$ and ${ }^{\# \# \#} P<0.001$, compared with the $1 \mathrm{~K}-1 \mathrm{C}$ control group

$(151.2 \pm 3.63 \mathrm{mmHg})$ (Fig. 7a). As shown in Fig. 7b, however, oral administration of HDR-2 at two doses $(150 \mathrm{mg} /$ $\mathrm{kg}$ and $300 \mathrm{mg} / \mathrm{kg})$ could significantly $(P<0.01)$ reduce the SBP in SHRs from the second week. Moreover, the SBP values in the two SHR/HDR-2 groups and the SHR/ Arg + GABA group at week 12 were significantly lower $(P<0.001)$ than those in the SHR group. The data were expressed as $\triangle \mathrm{SBP}$, which was the difference between the SBP on day 0 and the SBP measured every week after the beginning of the experiment. The $\triangle \mathrm{SBP}$ value in the SHR control group at week $12(47.7 \pm 2.22 \mathrm{mmHg})$ was significantly higher $(P<0.001)$ than that in the WKY group $(13.5 \pm 1.26 \mathrm{mmHg})$. The HDR-2-treated groups exhibited significant decreases in the mean $\triangle \mathrm{SBP}$ in SHRs. Furthermore, the $\triangle \mathrm{SBP}$ of the rats treated with HDR-2 $(300 \mathrm{mg} / \mathrm{kg})$ was similar to that of rats on grouping day (0 day) until 12 weeks (Fig. 7b). Interestingly, the ${ }_{\mathrm{L}}$-arginine+GABA group also showed significant decreases in SBP compared with the SHR group $(P<0.001)$. The heart rate also significantly decreased in the HDR-2-treated groups after 5 weeks (aged 12 weeks) compared with the 12-week-old SHR control group (Fig. 7c). However, the heart rates of all HDR-2-treated groups were not significantly different from that of the
WKY group (aged 6 weeks) or SHR control group (aged 6 weeks). As expected, the body weights of the rats in all groups increased over time, although no significant differences in body weight gain were observed among the groups during the six-weeks experimental period (Table 2). After sacrifice, the average weights of the heart, kidney, liver and spleen were not significantly different among the SHR groups. However, SHRs had a higher heart weight index, kidney weight index and liver weight index than WKYs, and these parameters were not altered by HDR-2 treatments. In fact, SHRs are characterized by relative increases in heart and kidney weights compared with normotensive WKY rats [39].

\section{Antihypertensive action of single oral administration of HDR-2}

In the short-term test, the antihypertensive activity of HDR-2 was evaluated by measuring the SBP in SHRs at $0,0.5,1,1.5,2,2.5$ and $3 \mathrm{~h}$ after oral administration, as shown in Fig. 8. Half an hour after administration of HDR-2 (150 and $300 \mathrm{mg} / \mathrm{kg} \mathrm{BW)} \mathrm{or} \mathrm{a} \mathrm{mixture} \mathrm{of} \mathrm{L}^{\text {-argi- }}$ nine and GABA $(10 \mathrm{mg} / \mathrm{kg} B W)$, the blood pressure values of the three groups had undergone a slight decrease. Moreover, the lowering effect of HDR-2 on SBP showed 


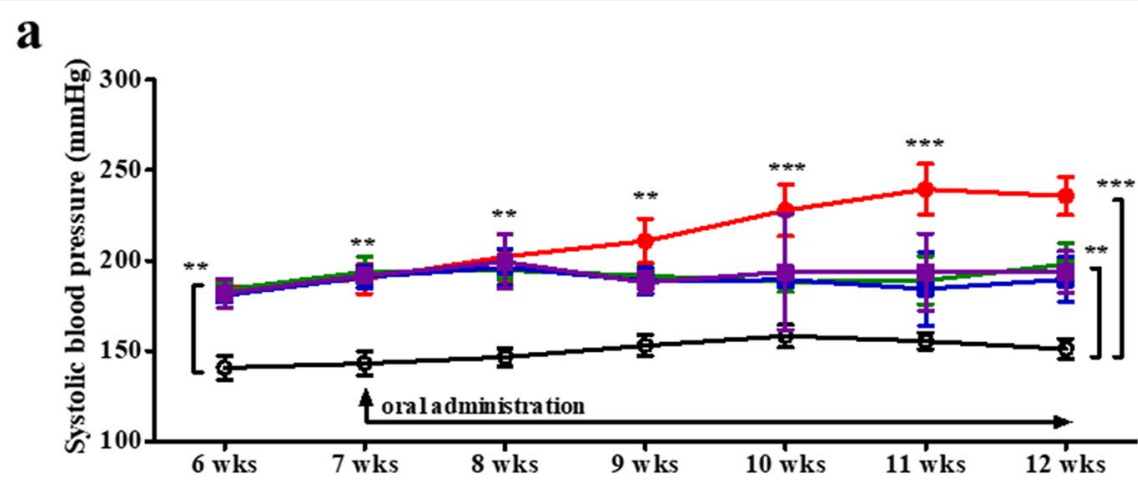

b
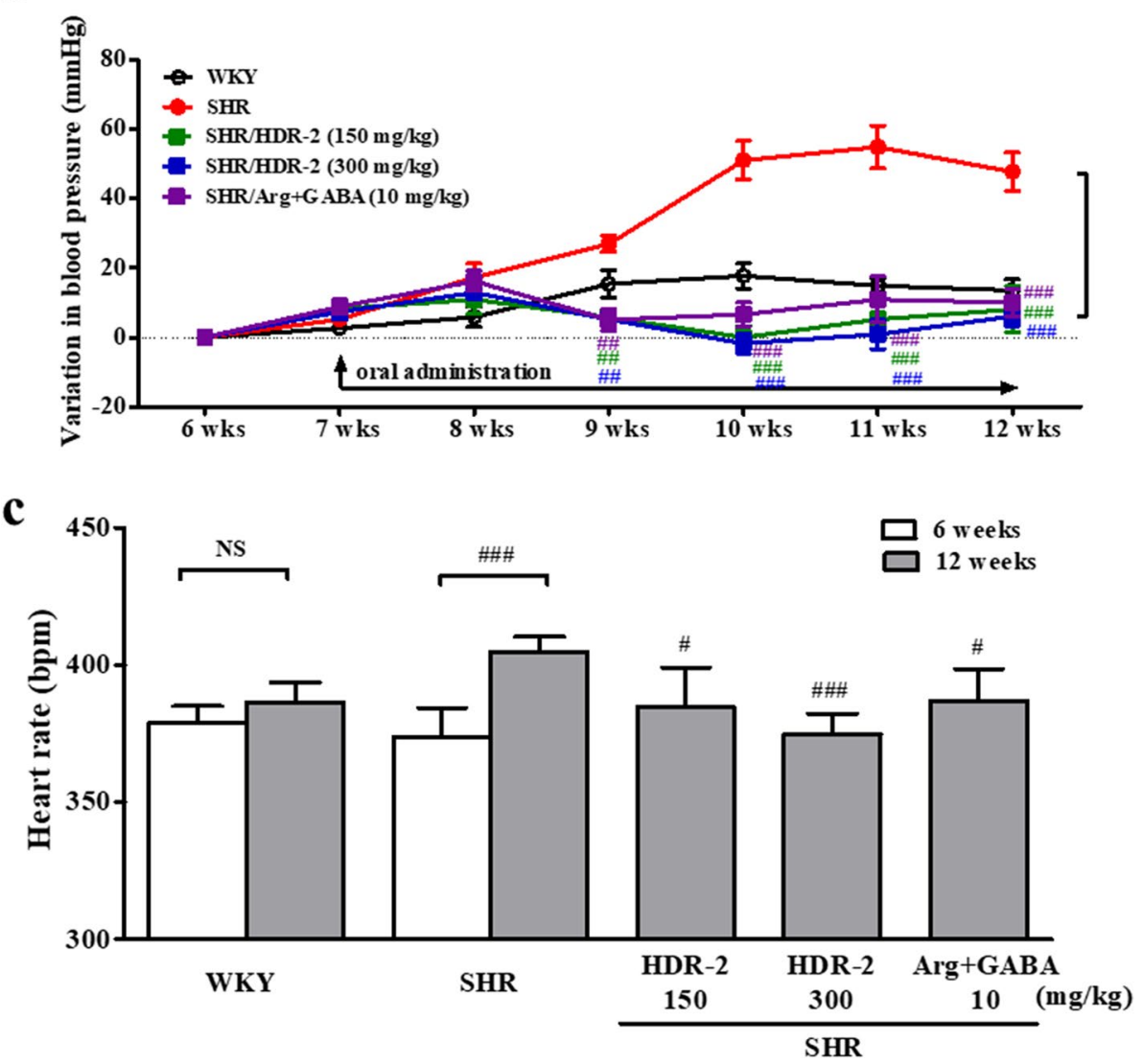

Fig. 7 HDR-2 reduces blood pressure in spontaneously hypertensive rats (SHRs). Effects of long-term oral administration of HDR-2 on (a) systolic blood pressure $(\mathrm{SBP}, \mathrm{mmHg}),(\mathbf{b})$ variation in blood pressure $(\triangle \mathrm{SBP}, \mathrm{mmHg})$ and $(\mathbf{c})$ heart rate $(\mathrm{HR}, \mathrm{bpm})$ as measured by tail-cuff plethysmography in SHRs. SHRs in the low-dose (150 mg/kg BW) and high-dose (300 mg/kg BW) groups were orally administered HDR-2 every day over a period

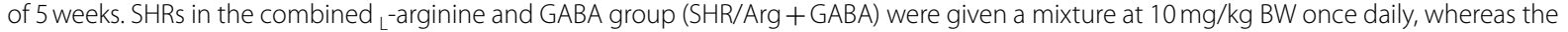
SHRs and WKYs in the control groups were given saline $(0.5 \mathrm{~mL})$. Values are expressed as the mean \pm SD. ${ }^{* *}$ and ${ }^{* * *}$ indicate $P<0.01$ and $P<0.001$, respectively, compared with the WKY control group (WKY); \#\# and \#\#\# indicate $P<0.01$ and $P<0.001$, respectively, compared with the SHR control group. NS indicates not significant

an obvious dose-dependent relationship throughout the experimental period. The maximum decline exhibited by the three groups was observed at $2.5-3 \mathrm{~h}$, and the decreases in SBP were $18.0 \pm 8.71 \mathrm{mmHg}(2.5 \mathrm{~h})$, $40.0 \pm 3.61 \mathrm{mmHg}(3 \mathrm{~h})$ and $27.0 \pm 4.58 \mathrm{mmHg}(3 \mathrm{~h})$.

\section{Evaluation of the renin-angiotensin-aldosterone system} (RAAS)

The in vivo ACE activities of plasma and lung tissue from the test groups were assessed 5 weeks after administration of HDR-2 (150 and $300 \mathrm{mg} / \mathrm{kg} \mathrm{BW}$ ) 
Table 2 Body, kidney, liver, spleen and heart weights of SHRs for six weeks. Data are expressed as the mean \pm SD. ${ }^{* *} P<0.01$ compared with the Wistar Kyoto rat (WKY) group

\begin{tabular}{|c|c|c|c|c|c|c|c|}
\hline \multirow[t]{2}{*}{ Group } & \multirow[t]{2}{*}{ Number } & \multicolumn{2}{|c|}{ Body Weight (g) } & \multicolumn{4}{|c|}{ Weight Index (mg/g of BW ratio) } \\
\hline & & Week-6 & Week-12 & Heart & Kidney & Liver & Spleen \\
\hline WKY & $n=5$ & $132.7 \pm 9.35$ & $319.3 \pm 12.96$ & $2.47 \pm 0.06$ & $5.84 \pm 0.23$ & $28.12 \pm 1.61$ & $2.68 \pm 0.12$ \\
\hline SHR & $n=5$ & $123.2 \pm 4.81$ & $289.9 \pm 6.58$ & $4.19 \pm 0.15^{* *}$ & $7.57 \pm 0.03^{* *}$ & $40.68 \pm 1.80^{* *}$ & $1.78 \pm 0.03^{* *}$ \\
\hline SHR/HDR-2 (150 mg/kg) & $n=5$ & $124.9 \pm 5.27$ & $289.7 \pm 4.97$ & $4.72 \pm 0.03$ & $7.53 \pm 0.16$ & $42.93 \pm 2.72$ & $1.76 \pm 0.02$ \\
\hline SHR/HDR-2 (300 mg/kg) & $n=5$ & $121.2 \pm 5.42$ & $277.4 \pm 4.37$ & $4.24 \pm 0.14$ & $8.12 \pm 0.20$ & $43.83 \pm 1.99$ & $1.83 \pm 0.03$ \\
\hline SHR/Arg + GABA (10 mg/kg) & $n=5$ & $122.8 \pm 4.81$ & $281.9 \pm 2.38$ & $4.26 \pm 0.15$ & $8.24 \pm 0.15$ & $42.77 \pm 1.30$ & $1.97 \pm 0.02$ \\
\hline
\end{tabular}

\section{a}

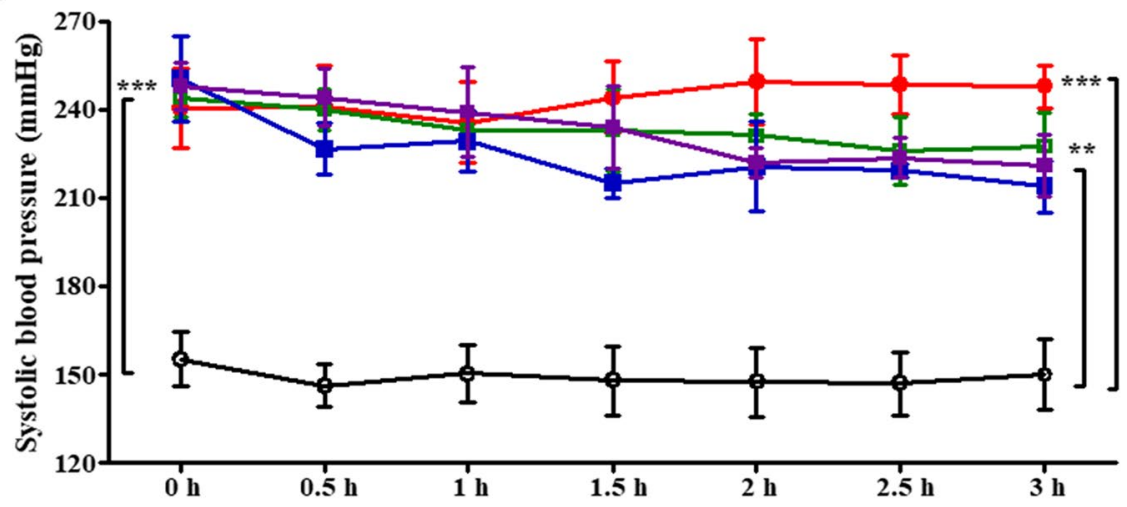

b

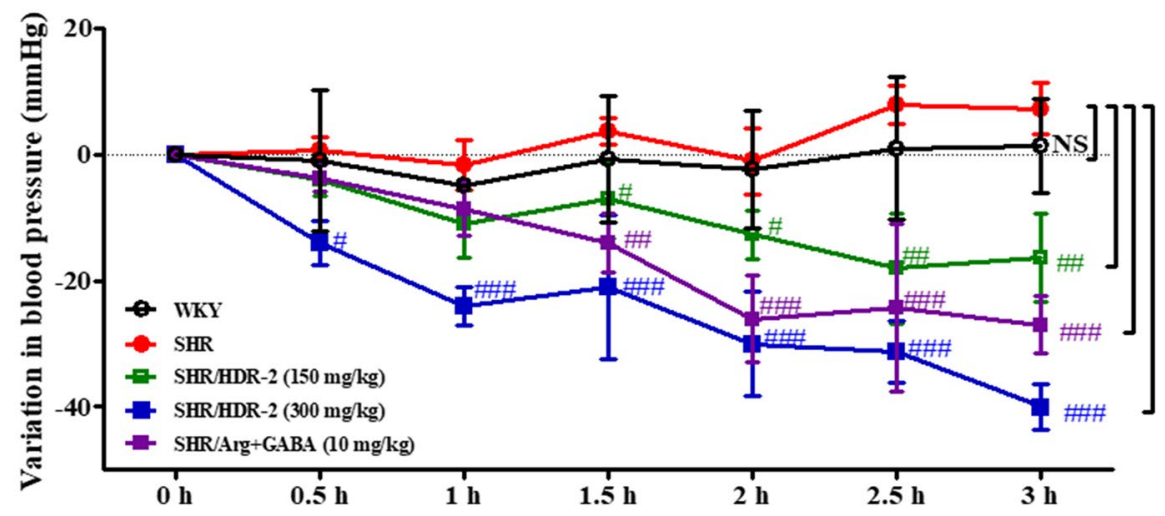

Fig. 8 Changes in systolic blood pressure (SBP) of spontaneously hypertensive rats (SHRs) after a single oral administration of HDR-2. Single oral administrations were performed at a dosage of $150 \mathrm{mg} \mathrm{HDR}-2 / \mathrm{kg}$ body weight, $300 \mathrm{mg} \mathrm{HDR}-2 / \mathrm{kg}$ body weight and $10 \mathrm{mg}$ mixture of Larginine and GABA/kg body weight. SBP was measured $0,0.5,1,1.5,2,2.5$ and $3 \mathrm{~h}$ after administration. Values are expressed as the mean \pm SD. ${ }^{* * *}$ indicates $P<0.001$ compared with the WKY control group (WKY); \#, \#\# and \#\#\# indicate $P<0.05, P<0.01$ and $P<0.001$, respectively, compared with the SHR control group. NS indicates not significant

and a mixture of ${ }_{\mathrm{L}}$-arginine and GABA $(10 \mathrm{mg} / \mathrm{kg} \mathrm{BW})$ (Fig. 9a, b). Examination of plasma and lung ACE activity showed less activity in the HDR-2-treated groups and

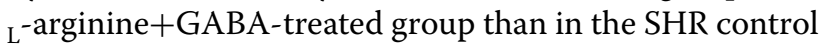
group. At the $150 \mathrm{mg} / \mathrm{kg}$ dose of HDR-2, the mean ACE levels in plasma and lung were $2.88 \pm 0.32 \mathrm{ng} / \mathrm{mL}$ and
$1.33 \pm 0.12 \mathrm{ng} / \mathrm{mg}$ of protein, respectively. At the $300 \mathrm{mg} /$ $\mathrm{kg}$ dose of HDR-2, the mean ACE levels in plasma and lung were $2.30 \pm 0.67 \mathrm{ng} / \mathrm{mL}$ and $1.31 \pm 0.05 \mathrm{ng} / \mathrm{mg}$ of protein, respectively. Moreover, at the $10 \mathrm{mg} / \mathrm{kg}$ dose of $\mathrm{L}^{\text {-arginine }}+\mathrm{GABA}$, the mean ACE levels in plasma and lung were $2.73 \pm 0.28 \mathrm{ng} / \mathrm{mL}$ and $1.27 \pm 0.09 \mathrm{ng} / \mathrm{mg}$ of 

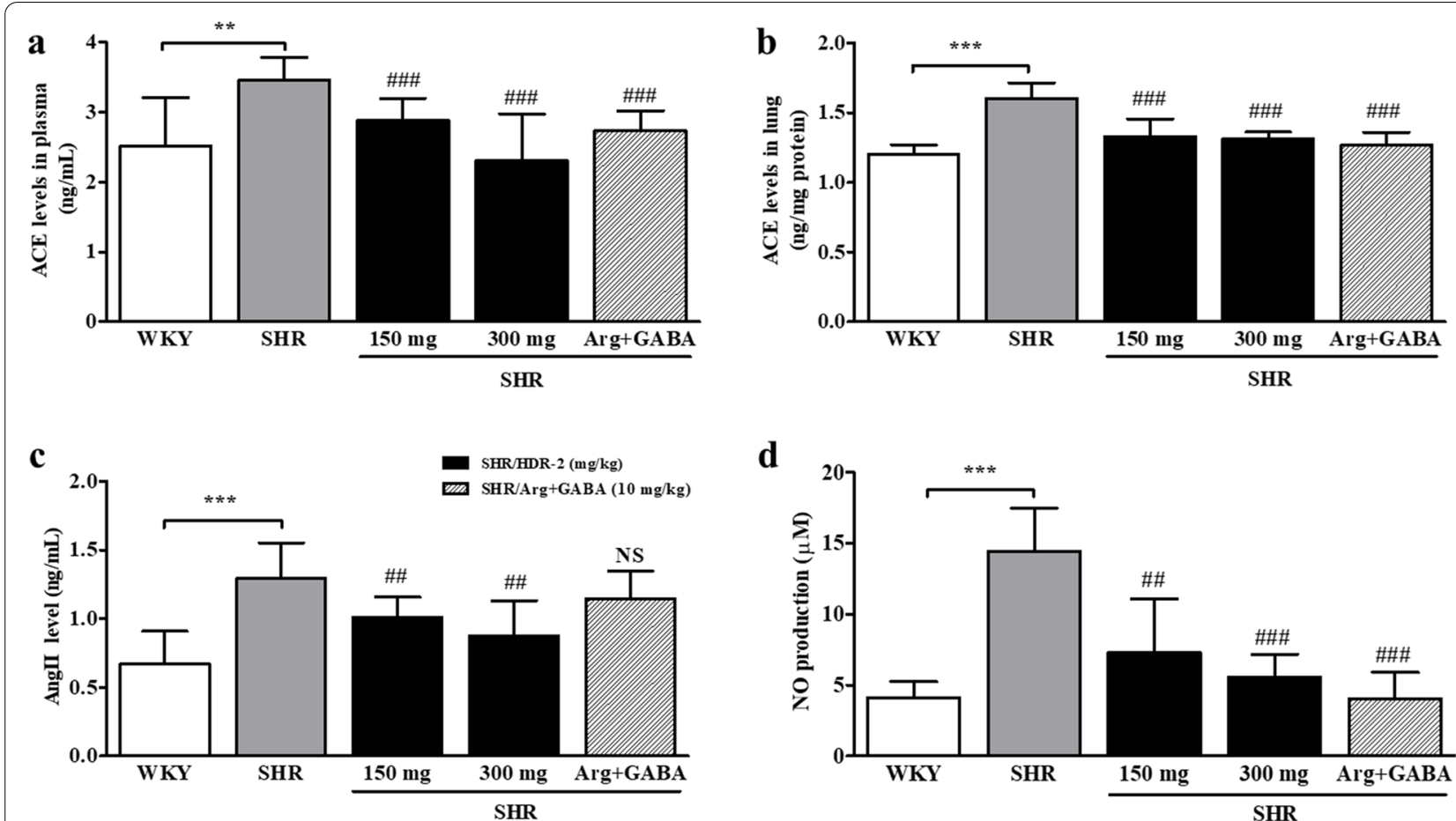

d

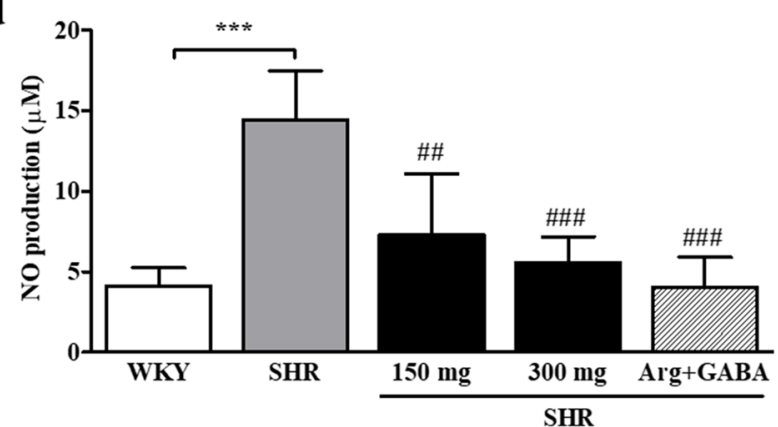

Fig. 9 a Plasma ACE levels in the indicated treatment groups. b Lung ACE levels in the indicated treatment groups. c Plasma Angll levels in the indicated treatment groups. $\mathbf{d}$ Plasma nitric oxide (NO) levels in the indicated treatment groups. The values represent the means $\pm S D ;{ }^{* *} P<0.01$ and ${ }^{* * *} P<0.001$, compared with the Wistar Kyoto rat (WKY) group; ${ }^{\# \#} P<0.01$ and ${ }^{\# \#} P<0.001$, compared with the spontaneously hypertensive rat (SHR)-control group

protein, respectively. In contrast, those of the SHR control group were $3.46 \pm 0.32 \mathrm{ng} / \mathrm{mL}$ and $1.60 \pm 0.11 \mathrm{ng} /$ $\mathrm{mg}$ of protein, respectively. However, no significant differences were observed in the ACE activities between the $150 \mathrm{mg} / \mathrm{kg}$ and $300 \mathrm{mg} / \mathrm{kg}$ treated groups. All HDR-2 and $\mathrm{L}_{\text {-arginine }}+\mathrm{GABA}$ treatments significantly lowered ACE levels in plasma and lung tissue from SHRs $(P<0.001)$. Moreover, the beneficial effect of HDR-2 in relieving hypertension was also evidenced by the reduction in AngII concentrations in plasma samples (Fig. 9c). Compared with control SHRs, HDR-2-treated SHRs demonstrated significantly reduced plasma AngII levels at 5 weeks after treatment $(P<0.01)$. However, the concentrations of AngII in SHR plasma samples were not significantly decreased in SHRs treated with $\mathrm{L}^{\text {-arginine and }}$ GABA $(P>0.05)$.

\section{The effect of HDR-2 on plasma NO production}

We investigated plasma NO concentrations by HDR-2 administration (Fig. 9d). The plasma NO concentration in the SHR control rat was significantly increased compared with that in the WKY rat $(14.42 \pm 3.05$ and $4.11 \pm 1.13 \mu \mathrm{M}$, respectively; $P<0.001)$. Moreover, the NO concentrations in the SHR/HDR-2 (150 and $300 \mathrm{mg} /$ $\mathrm{kg})$ rats were significantly decreased $(7.26 \pm 3.82$ and
$5.57 \pm 1.60 \mu \mathrm{M}$, respectively) in serum in a dose-dependent manner compared to those in the SHR control rat.

\section{HDR-2 stimulates the expression and phosphorylation of eNOS in aortic segments}

eNOS serves an important basal regulatory function in the vasculature. When subjected to stimuli such as shear stress or ACh, eNOS, which is constitutively expressed in endothelial cells, oxidizes ${ }_{L}$-arginine to generate ${ }_{L}$-citrulline and NO. ${ }_{L}$-Arginine is one of the major biologically active components of $\mathrm{Hy}-D P$ and is regarded as the main compound responsible for its many pharmacological actions, including enhancement of eNOS expression, phosphorylation and NO production. We examined eNOS phosphorylation by western blotting analysis of tissue homogenate from the aortae of both WKY rats and SHRs after administration of HDR-2. As shown in Fig. 10, no significant difference in the level of eNOS expression was observed between samples from the aortae of the SHR control group and WKY group $(P>0.05)$. HDR-2 treatment increased the level of eNOS expression compared to that observed in the SHR control group (values of HDR-2 $150 \mathrm{mg} / \mathrm{kg}$ and HDR-2 $300 \mathrm{mg} / \mathrm{kg}$ were $150.6 \pm 48.19 \%$ and $326.4 \pm 113.90 \%$ higher than those of SHR control group, respectively). Administration 


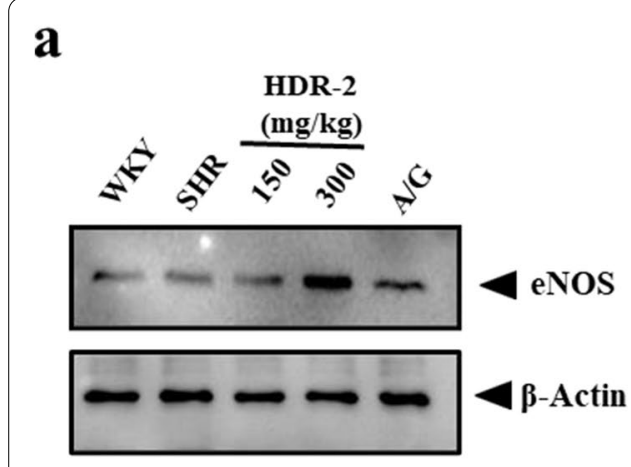

b
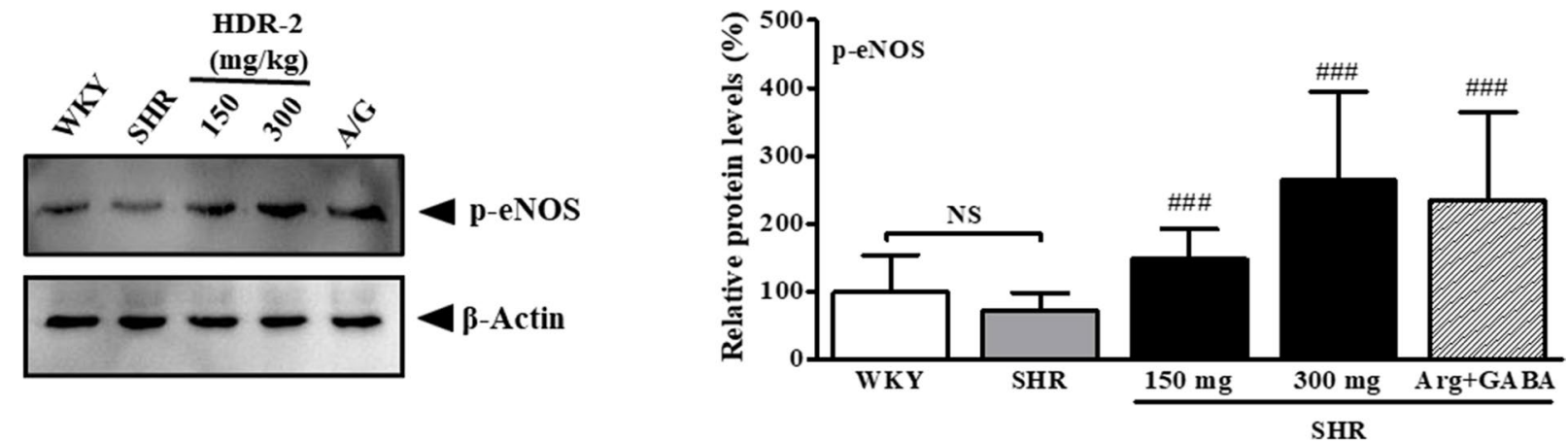

Fig. 10 Effects of HDR-2 on the phosphorylation of eNOS (p-eNOS) and the expression of eNOS proteins in the aortae of the SHR control group and WKY group. A The protein expression and phosphorylation levels of eNOS in aortae were measured by western blotting. B The bar graphs indicate the average eNOS and $\mathrm{p}$-eNOS levels. The data are expressed as the mean \pm SD. $P$ values for comparisons with SHR control groups are denoted as ${ }^{\#} P<0.05$, ${ }^{\# \#} P<0.01$ and ${ }^{\# \# \#} P<0.001$, and those for comparisons with HDR-2 (300 mg/kg) groups are denoted as ${ }^{*} P<0.05$

of a mixture of ${ }_{\mathrm{L}}$-arginine and GABA also stimulated the expression of eNOS in SHRs $(P<0.05)$. In addition, the efficiency of HDR-2 $(300 \mathrm{mg} / \mathrm{kg})$ to stimulate eNOS expression was much higher than that of the mixture of

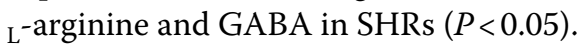

In addition, our data show that Ser-1177 phosphorylation of eNOS (p-eNOS) is reduced in the aortae of the SHR control group $(72.11 \pm 25.99 \%$ lower than WKY group values; $P>0.05$, NS). Treatment with HDR-2 increased the levels of eNOS phosphorylation relative to the levels observed in rats in the SHR control group (values of HDR-2 $150 \mathrm{mg} / \mathrm{kg}$ and HDR-2 $300 \mathrm{mg} / \mathrm{kg}$ were $148.9 \pm 43.57 \%$ and $254.9 \pm 129.30 \%$ higher, respectively, than those of SHR control group). The level of eNOS phosphorylation also increased in SHRs after administration of a mixture of ${ }_{\mathrm{L}}$-arginine and GABA $(P<0.001)$.

\section{HDR-2 improved the vascular relaxation response in SHR aortae}

The effect of HDR-2 on vascular function in SHRs was evaluated as one of the possible mechanisms for its antihypertensive effects. To validate endothelium-dependent relaxation, we treated $\mathrm{ACh}\left(10^{-9}-10^{-3} \mathrm{M}\right)$ to aortic tissue that had been precontracted with PHE $(10 \mu \mathrm{M})$. In the SHR control group, the relaxation response at $10^{-9}-10^{-3} \mathrm{M}$ ACh was significantly lower than that in the WKY control rats $(P<0.001)$ (Fig. 11a). In vivo treatment with HDR-2 at 150 and $300 \mathrm{mg} / \mathrm{kg}$ significantly improved the impaired ACh $(1 \mathrm{mM})$-induced relaxation in SHR aortae $(P<0.01, P<0.01$, respectively). The effective concentrations causing $50 \%$ relaxation $\left(E C_{50}\right)$ of SHR/HDR-2 $(150 \mathrm{mg} / \mathrm{kg})$ and SHR/HDR-2 $(300 \mathrm{mg} /$ $\mathrm{kg}$ ) were $7.71 \pm 0.21 \mu \mathrm{M}$ and $7.18 \pm 0.32 \mu \mathrm{M}$, respectively, which were significantly lower $(P<0.01)$ than that in the SHR control group ( $\mathrm{EC}_{50}$ value: $\left.15.66 \pm 0.20 \mu \mathrm{M}\right)$. Figure 11b shows the results of SNP-induced relaxation in each group of denuded aortic rings. SNP-induced endothelium-independent relaxation and the respective $\mathrm{EC}_{50}$ values were also significantly different among the SHR control group $(26.67 \pm 0.15 \mu \mathrm{M})$, SHR/HDR-2 $(150 \mathrm{mg} / \mathrm{kg})$ group $(10.09 \pm 0.16 \mu \mathrm{M})$ and SHR/HDR-2 $(300 \mathrm{mg} / \mathrm{kg})$ group $(12.40 \pm 0.14 \mu \mathrm{M})$. HDR-2 administration improved endothelium-dependent and endothelium-independent vasorelaxation in SHR thoracic aortae. 

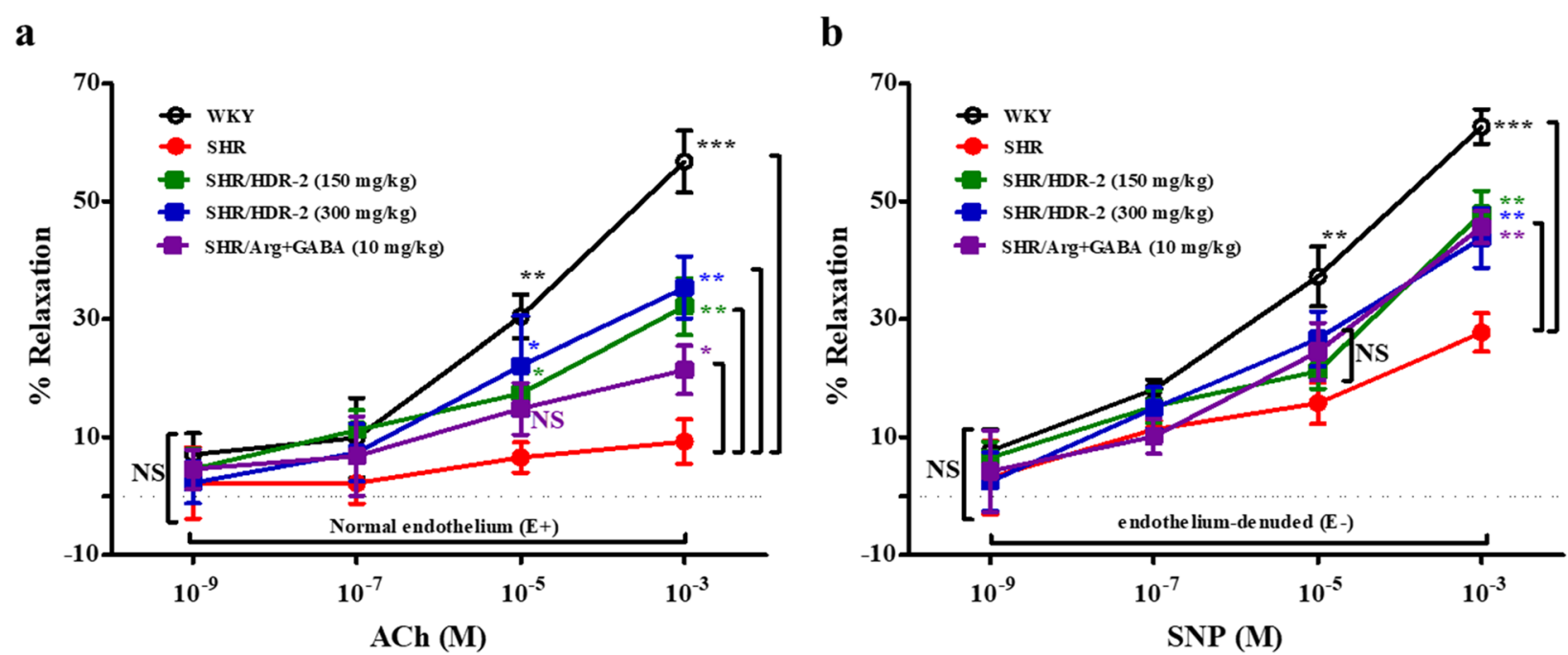

Fig. 11 a Endothelium-dependent relaxation curve induced by acetylcholine (ACh) and (b) endothelium-independent relaxation curve induced by sodium nitroprusside (SNP) in thoracic aortic rings from the indicated treatment groups. The values represent the means \pm SD; ${ }^{*} P<0.05,{ }^{* *} P<0.01$ and ${ }^{* * *} P<0.001$, compared with the spontaneously hypertensive rat (SHR)-control group. NS indicates not significant

\section{Discussion}

Our previous research has demonstrated that both $\mathrm{Hy}-D P$ and 5- $u$ RCK have vasodilatory activities [24]. In the present study, we prepared a novel formulation, designated HDR-2, which contained 5-uRCK and Hy-DP, and administered it to two different animal models of hypertension. We found that HDR-2 treatment increased eNOS expression and phosphorylation and decreased blood pressure in hypertensive rats. These results indicate that HDR-2 administration has the potential to reduce blood pressure and prevent CVDs.

Both the vascular endothelium and vascular smooth muscle play important roles in regulating the function of the cardio-cerebrovascular system. Enhanced NO is a possible endothelium-dependent mechanism of vasodilation. As in our previous study, incubation of thoracic aortae with $L^{-N A M E, ~ a ~ N O S ~ i n h i b i t o r, ~ r e d u c e d ~ v a s o-~}$ dilation by both Hy-DP and 5-uRCK [24], suggesting a contribution of NO to relaxation in both groups. In this study, HDR-2-induced vasodilation was also reduced, but not completely inhibited, by treatment with ${ }_{\mathrm{L}}-\mathrm{NAME}$ and ODQ in rat aortic rings with intact endothelium. Furthermore, removal of the endothelium from the aortic ring did not completely inhibit HDR-2-induced relaxation when the rings were preincubated with PHE. This finding suggests that HDR-2-induced relaxation involves both endothelium-dependent and endothelium-independent mechanisms, which is in accordance with our previous findings [24].

$\mathrm{NO}$ is a major endothelium-dependent relaxation factor, and its production by vascular endothelial cells plays a critical role in the regulation of vascular motor tone and the stability of blood flow as well as blood pressure $[40,41]$. NO is synthesized by vascular endothelial cells

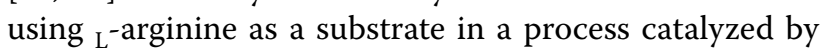
NOS [42] and induces vascular smooth muscle relaxation by activation of guanylate cyclase [43]. Because it is an isoform of NOS that produces NO, eNOS also plays an important role in regulating systemic blood pressure [44]. The intracellular concentration of ${ }_{\mathrm{L}}$-arginine normally greatly exceeds the level that is required for maximal enzyme kinetics of NOS; the Michaelis constant $(\mathrm{Km})$ of ${ }_{\mathrm{L}}$-arginine for NOS is $2.9 \mu \mathrm{mol} / \mathrm{L}$, whereas the intra-

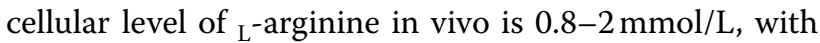
a plasma concentration in the range of $60-350 \mu \mathrm{mol} / \mathrm{L}$ $[45,46]$. Nonetheless, $L_{\text {-arginine supplementation has }}$ been shown to improve endothelial function, reduce atherosclerosis progression and alter autonomic function, all consistent with enhanced NO synthesis [45, 47]. This is termed the ${ }_{\mathrm{L}}$-arginine paradox and can probably be best explained by compartmentalization of NOS and a relative ${ }_{\mathrm{L}}$-arginine deficiency rather than an absolute deficiency. The plasma ${ }_{\mathrm{L}}$-arginine level was lower in the SHRs than in the WKY rats but was increased to a comparable level following ${ }_{L}$-arginine supplementation [48]. We developed and reported a technique for amplifying the ${ }_{\mathrm{L}}$-arginine content of $D P$ using the enzymatic hydrolysis method [16]. Furthermore, our previous study showed the effects of $\mathrm{Hy}-\mathrm{DP}$ on vascular relaxation, eNOS expression and NO production in vitro [24]. In the present study, ${ }_{L}$-arginine contained in HDR-2 significantly decreased SBP in the hypertensive rat models and improved vascular 
function. However, the exact molecular mechanism of HDR-2-activated ${ }_{\mathrm{L}}$-arginine transport remains to be further studied. Moreover, the results of the present study also showed that HDR-2 induces a dose-dependent chronic hypotensive effect on SHR, significantly reducing SBP as well as heart rate, which was significant at 150 and $300 \mathrm{mg} / \mathrm{kg}$. For detailed mechanisms involving these results, HDR-2 should be examined for possible mechanisms using atropine (a nonselective muscarinic antagonist) and hexamethonium (an autonomic ganglion blocker). Therefore, it is hypothesized that the detailed mechanism underlying the heart rate reduction effect of HDR-2 treatment is based on the mechanisms described above.

The RAAS plays an important role in controlling blood pressure in the body [49]. In this system, ACE converts AngI to AngII, which increases blood pressure by causing the constriction of blood vessels [50, 51]. AngII also promotes oxidative stress, inflammation and fibrosis [52]. Furthermore, AngII is an important mediator of cardiovascular remodeling, which not only increases blood pressure but also enhances the generation of reactive oxygen species (ROS) [53]. Inhibition of ACE is a widely used strategy for the treatment of hypertension [54], so the food and pharmaceutical industries have an ongoing interest in new sources of ACE inhibitors with antihypertensive activity [55]. The SHR is considered to be a renin-independent model of hypertension in which plasma AngII levels are not elevated [56]. Nevertheless, ACE inhibitors have proven to be potent and effective agents in SHRs for the reduction in blood pressure and regression of several abnormalities, including cardiac and renal hypertrophy and endothelial dysfunction, that are developed in this model of genetic hypertension $[57,58]$. This disparity can be understood if we consider that their antihypertensive effects are more closely related to the inhibition of tissue, rather than plasma, ACE [58, 59]. In fact, we found that chronic treatment with HDR-2 significantly reduced ACE activities in plasma and target organs for hypertension, such as lung tissue. Since HDR-2 was initially identified as an in vitro and in vivo ACE inhibitor, plasma AngII levels were assessed in both HDR-2-treated and untreated animals. Plasma AngII levels were significantly different between HDR-2-treated and untreated SHRs (Fig. 9c), indicating that HDR-2 may work as an $\mathrm{ACE}$ inhibitor in reducing blood pressure in hypertensive rats. Furthermore, in $1 \mathrm{~K}-1 \mathrm{C}$ hypertensive rats (regarded as a model of RAAS-dependent hypertension) (Fig. 6c), hypertension was also significantly responsive to HDR-2. In this study, plasma AngII levels in the $1 \mathrm{~K}-1 \mathrm{C}$ hypertensive rats and SHRs were significantly higher than those in the WKY normal control rats, suggesting that the RAAS was activated in the hypertensive model rats and confirming that the RAAS plays an important role in the pathological process of hypertension.

According to a previous studies, single oral administration of GABA at a concentration of $0.5 \mathrm{mg} / \mathrm{kg}$ to SHR significantly lowered systolic blood pressure [22], and the antihypertensive activity of GABA was significant at doses ranging from 0.05 to $5 \mathrm{mg} / \mathrm{kg}$ [23]. Our previous study reported that $100 \mathrm{mg}$ of $\mathrm{Hy}-\mathrm{DP}$ contains $2.8 \mathrm{mg}$ of GABA, as estimated from the HPLC data [24]. We found that $\mathrm{Hy}-D P$ contains a sufficient concentration of GABA to decrease blood pressure in SHRs. Furthermore, the extracts $D P, \mathrm{Hy}-D P$ and $5-u \mathrm{RCK}$ contained $2.61 \pm 1.02 \mathrm{mg} / \mathrm{g}, 17.77 \pm 1.36 \mathrm{mg} / \mathrm{g}$ and $1.63 \pm 0.25 \mathrm{mg} / \mathrm{g}$ $\mathrm{L}$-arginine, respectively. The HDR-2 samples used in this study contained $\mathrm{L}$-arginine and GABA, and the ingested amounts in the in vivo administration test were $3.7 \mathrm{mg}$ and $5.7 \mathrm{mg}$ of ${ }_{\mathrm{L}}$-arginine and GABA per $\mathrm{kg} \cdot \mathrm{BW}$, respectively. These studies showed that the blood pressurelowering effect of these compounds is significant. Thus, $\mathrm{L}$-arginine and GABA were potentially responsible for the antihypertensive effect. Although the mechanism underlying the hypotensive action of systemically administered GABA has not yet been fully elucidated, several hypotheses have been postulated. One of them postulates that because GABA rarely crosses the blood-brain barrier, this molecule acts not in the central nervous system but in the peripheral nervous system [60].

In this study, the chronic effective dose of HDR-2 in $1 \mathrm{~K}-1 \mathrm{C}$ rats and SHRs was $150-300 \mathrm{mg} / \mathrm{kg}$ BW per day. The chronic effective dose for an adult person weighing $60 \mathrm{~kg}$ was estimated to be $1.4-2.9 \mathrm{~g} /$ day of HDR-2, based on Kleiber's law [61, 62]. However, it seemed to have a sufficient significant effect in the group treated with $150 \mathrm{mg} / \mathrm{kg}$, so it can be expected to be effective even at lower concentrations. Therefore, further studies at lower concentrations are needed. HDR-2 can potentially serve as an important antihypertensive food or drug.

The expression and activity of NOS is altered in hypertensive animal models such as SHRs, and earlier studies have shown increased ROS, enhanced NOS expression, and NO production in SHRs [63]. In this study, the SHR control group also had higher basal plasma NO levels than the WKY group (Fig. 6d). Our results are consistent with previous studies showing that higher plasma NO levels in the SHR control group may reflect increased basal expression of iNOS [64] and oxidative stressinduced activation of iNOS [65]. The cause of vascular endothelial dysfunction of SHR is the increased activity of nicotinamide adenine dinucleotide phosphate oxidase (NADPH oxidase, NOX) in cells and the resulting oxidative stress induce iNOS and decrease NO bioavailability [66]. Furthermore, AngII stimulates ROS production mainly by activating NOXs in the vessel wall $[67,68]$. 
Moreover, NOX seems to contribute to ROS production in SHR endothelial cells regardless of AngII [69]. Increased eNOS activity and decreased NOX activity were involved in the improvement of vascular endothelial function in SHR [70], and the increase in eNOS expression and activation was strongly associated with elevated plasma NO levels in SHR [71]. Notably, a reduction in eNOS activity is known to be involved in the hypertensive state of SHR [72]. Consistent with the published information, our data show that eNOS phosphorylation is slightly reduced in the aortae of SHRs. Moreover, we found that HDR-2 significantly increased eNOS phosphorylation in the aortae of SHRs. Reduced eNOS and AKT phosphorylation are simultaneously present in the aortae of SHRs [73]. In this study, however, plasma total $\mathrm{NO}$ levels and eNOS expression and phosphorylation levels were assessed merely as a control for hypertensionassociated parameters. Therefore, further studies are required to confirm our findings.

Incubation of thoracic aortae with $\mathrm{L}$-NAME, an NOS inhibitor, reduced vasodilation in HDR-2, suggesting a contribution of $\mathrm{NO}$ to relaxation in HDR-2-treated groups (Fig. 1c). This NO-dependent vasodilation may be due to the enhanced NO bioavailability through scavenging of free radicals or increased $\mathrm{NO}$ production in the vasculature. Vascular relaxation due to SNP, an exogenous NO donor, was also significantly enhanced in the HDR-2-treated group compared to the untreated SHR group (Fig. 11b). This implies the involvement of either an endothelium-independent mechanism (in addition to endothelium-dependent mechanisms) or enhanced NO bioavailability in the HDR-2-treated group compared to the untreated SHR group.

In this study, HDR-2 treatment improved AChinduced endothelium dependence in isolated intact SHR thoracic aortae and SNP-induced endotheliumindependent relaxation in isolated denuded SHR thoracic aortae. However, although these findings suggest that HDR-2 is involved in blood pressure regulation in a partially endothelium-independent manner, it is currently unclear whether HDR-2 is able to directly regulate vascular smooth muscle cell (VSMC) phenotypic switching and proliferation in hypertension. A recent study reported that transient receptor potential vanilloid 1 (TRPV1) cation channel activation elevates the phosphorylation of PKA and eNOS in endothelial cells and plasma NO concentration, improves endotheliumdependent relaxation in mesenteric arteries, and lowers arterial pressure in genetically hypertensive rats [74, 75]. Thus, endothelial TRPV1 activation can be considered a potential strategy for the management of hypertension. To fill these gaps, therefore, we will investigate the detailed molecular mechanism of HDR-2 on phenotypic switching and proliferation of VSMCs and chronic activation of TRPV1 in hypertension.

\section{Conclusions}

The present study, to the best of our knowledge, is the first to compare the effects of long-term treatment with HDR-2 on vascular function in a $1 \mathrm{~K}-1 \mathrm{C}$ hypertensive rat model and SHRs through several mechanisms. The main finding of the study was that reduced blood pressure was concomitant with increased vasodilation, reduced nitrosative stress, ACE and AngII, and enhanced eNOS expression. While our findings are novel, further research is needed to ascertain the role of HDR-2 in mechanisms involved in endotheliumindependent vasorelaxation to achieve a comprehensive understanding of the underlying mechanisms. The findings from this study may establish the potential of natural products in the management of hypertension and associated complications.

\section{Abbreviations}

ACE: Angiotensin-converting enzyme; ACh: Acetylcholine chloride; CAMP: Cyclic 3',5'-adenosine monophosphate; cGMP: Cyclic 3',5'-guanosine monophosphate; CVD: Cardiovascular disease; DP: Dendropanax morbiferus H. Léveille extract; eNOS: Endothelial nitric oxide synthase; $\mathrm{EC}_{50}$ : Half maximal effective concentration; GABA: Y-Aminobutyric acid; GAPDH: Glyceraldehyde 3-phosphate dehydrogenase; GC: Guanylate cyclase; HDR-2: Composed of Hy-DP and 5-URCK in a 2:1 mass ratio; HUVEC: Human umbilical vein endothelial cell; $H y$-DP: Enzymatically hydrolyzed Dendropanax morbiferus $\mathrm{H}$. léveille extract; $I_{50}$ : Half maximal inhibitory concentration; iNOS: Inducible

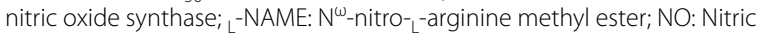
oxide; NOS: Nitric oxide synthase; nNOS: Neuronal nitric oxide synthase; ODQ: $1 \mathrm{H}-[1,2,4]$ oxadiazolo[4,3-a]quinoxalin-1-one; PDE: Phosphodiesterase; PHE: Phenylephrine hydrochloride; SHRs: Spontaneously hypertensive rats; $1 \mathrm{~K}-1 \mathrm{C}$ : 1-Kidney, 1-clip goldblatt hypertensive rats; 5-uRCK: 5\% Unripe Rubus coreanus miquel ethanol extract.

\section{Acknowledgments}

We sincerely appreciate other colleagues in our laboratory for their help and effort in this study.

\section{Authors' contributions}

SP, KHL, JSK and SK participated in research design. KHL and EK contributed new regents or analytical tools. SP, HC, GJ and KHL performed data analysis. WSK, CN and SK wrote or contributed to the writing of the manuscript. All authors read and approved the final manuscript.

\section{Funding}

This research was supported by a grant from the Korea Institute of Planning \& Evaluation for Technology in Food, Agriculture Forestry \& Fisheries (IPET) through the High Value-added Food Technology Development Program (grant number: 316065-3 and 116032-3). The funding body did not play a role in the study design, performance, data collection and analysis, decision to publish, or preparation/writing of the manuscript. The publication fee is supported by the former (316065-3).

Availability of data and materials

All data and analyses in the current study are available from the corresponding author upon reasonable request. 


\section{Declarations}

\section{Ethics approval and consent to participate}

The experiment was conducted according to the Directive 2010/63/EU of the European Parliament and of the counsel on the protection of animals used for scientific purposes [34].

The study was approved by the institutional animal care and use committee (IACUC) of the Bioresources and Technology (B\&Tech) Co., Ltd., Republic of Korea (Approval number: BT-002-2018). All efforts were made to minimize animal suffering and to reduce the number of animals used.

\section{Consent for publication}

All the participating authors read the manuscript and gave consent for publication.

\section{Competing interests}

The authors declare that they have no competing interests.

\section{Author details}

${ }^{1}$ Central R\&D Center, Bioresources and Technology (B\&Tech) Co., Ltd., 257, Jebong-ro, Buk-gu, Gwangju 61239, South Korea. ${ }^{2}$ College of Korean Medicine, Dongshin University, 185 Geonjae-ro, Naju-si, Jeollanam-do 58245, Republic of Korea.

Received: 22 June 2020 Accepted: 8 October 2021

Published online: 28 October 2021

\section{References}

1. MacMahon S, Peto R, Cutler J, et al. Blood pressure, stroke, and coronary heart disease. Part 1, prolonged differences in blood pressure: prospective observational studies corrected for the regression dilution bias. Lancet. 1990;335(8692):765-74. https://doi.org/10.1016/0140-6736(90) 90878-9.

2. Stamler J, Stamler R, Neaton JD. Blood pressure, systolic and diastolic, and cardiovascular risks. US population data. Arch Intern Med. 1993;153(5):598-615. https://doi.org/10.1001/archinte.153.5.598.

3. Kannel WB. Blood pressure as a cardiovascular risk factor: prevention and treatment. JAMA. 1996;275(20):1571-6. https://doi.org/10.1001/jama. 1996.03530440051036

4. World Health Organizarion. A global brief hypertension: silent killer, global public health crisis-World health day 2013. Geneva: WHO Press; 2013.

5. Soltani Z, Washco V, Morse S, Reisin E. The impacts of obesity on the cardiovascular and renal systems: cascade of events and therapeutic approaches. Curr Hypertens Rep 2015;17(2):7. https://doi.org/10.1007/ s11906-014-0520-2

6. Geng X, Tian G, Zhang W, et al. A Tricholoma matsutake peptide with angiotensin converting enzyme inhibitory and antioxidative activities and antihypertensive effects in spontaneously hypertensive rats. Sci Rep 2016:6:24130. https://doi.org/10.1038/srep24130.

7. Bae K. The medicinal plants of Korea. Seoul: Kyo-Hak Publishing; 2000

8. Hyun TK, Kim MO, Lee H, et al. Evaluation of anti-oxidant and anticancer properties of Dendropanax morbifera Léveille. Food Chem 2013;141:1947-55. https://doi.org/10.1016/j.foodchem.2013.05.021.

9. Moon HI. Antidiabetic effects of dendropanoxide from leaves of Dendropanax morbifera Leveille in normal and streptozotocin-induced diabetic rats. Hum Exp Toxicol 2011;30:870-5. https://doi.org/10.1177/0960327110 382131.

10. Bae $D$, Kim J, Lee $S$, Choi E, Jung M-A, Jeong CS, Na J, Kim J, Kim S Hepatoprotective effects of aqueous extracts from leaves of Dendropanax morbifera Leveille against alcohol-induced hepatotoxicity in rats and in vitro anti-oxidant effects. Food Sci Biotechnol 2015;24:1495-1503. https://doi.org/10.1007/s10068-015-0193-X.

11. Hyun TK, Ko YJ, Kim EH, Chung IM, Kim JS. Anti-inflammatory activity and phenolic composition of Dendropanax morbifera leaf extracts. Ind Crop Prod 2015;74:263-270. https://doi.org/10.1016/j.indcrop.2015.05.002.

12. Lee KH, Na HJ, Song CK, et al. Quercetin quantification in a Jeju Dendropanax morbifera lev. Extract by varying different parts, harvest times, and extraction solvents. Korean J. Food Preserv 2018;25:344-350. https://doi org/10.11002/kjfp.2018.25.3.344

13. Perez A, Gonzalez-Manzano S, Jimenez R, et al. The flavonoid quercetin induces acute vasodilator effects in healthy volunteers: correlation with beta-glucuronidase activity. Pharmacol Res 2014;89:11-18. https://doi. org/10.1016/j.phrs.2014.07.005.

14. Edwards RL, Lyon T, Litwin SE, Rabovsky A, Symons JD, Jalili T. Quercetin reduces blood pressure in hypertensive subjects. J Nut 2007:137(11):2405-2411. https://doi.org/10.1093/jn/137.11.2405.

15. Najmanová I, Pourová J, Mladěnka P. A mixture of phenolic metabolites of quercetin can decrease elevated blood pressure of spontaneously hypertensive rats even in low doses. Nutrients. 2020;12(1):213. https://doi. org/10.3390/nu12010213.

16. Lee KH, Kim S. Optimal enzymatic hydrolysis conditions for increased production of ${ }_{L}$-arginine and GABA in Dendropanax morbifera lev. Leaves Korean J Food Preserv 2019;26:289-299. https://doi.org/10.11002/kjfp. 2019.26.3.289

17. Siasos G, Tousoulis D, Vlachopoulos $C$, et al. Short-term treatment with -arginine prevents the smoking-induced impairment of endothelial function and vascular elastic properties in young individuals. Int J Cardiol 2008;126:394-399. https://doi.org/10.1016/j.ijcard.2007.04.057.

18. Shimada M, Hasegawa T, Nishimura C, et al. Anti-hypertensive effect of Y-aminobutyric acid (GABA)-rich Chlorella on high-normal blood pressure and borderline hypertension in placebo-controlled double blind study. Clin Exp Hypertens 2009;31:342-354. https://doi.org/10.1080/10641 960902977908

19. Williford DJ, Hamilton BL, Souza JD, et al. Central nervous system mechanisms involving GABA influence arterial pressure and heart rate in the cat Circ Res 1980;47:80-88. https://doi.org/10.1161/01.res.47.1.80.

20. Abe Y, Umemura S, Sugimoto K, et al. Effect of green tea rich in Y-aminobutyric acid on blood pressure of dahl salt-sensitive rats. Am J Hypertens 1995;8:74-79. https://doi.org/10.1016/0895-7061(94)00141-w.

21. Aoki H, Furuya $Y$, Endo Y, Fujimoto K. Effect of $Y$-aminobutyric acidenriched tempeh-like fermented soybean (GABA-tempeh) on the blood pressure of spontaneously hypertensive rats. Biosci Biotechnol Biochem 2003;67:1806-08. https://doi.org/10.1271/bbb.67.1806.

22. Hayakawa K, Kimura M, Kamata K. Mechanism underlying $\gamma$-aminobutyric acid-induced antihypertensive effect in spontaneously hypertensive rats. Eur J Pharmacol 2002;438:107-113. https://doi.org/10.1016/s00142999(02)01294-3.

23. Hayakawa K, Kimura M, Kasaha K, et al. Effect of a Y-aminobutyric acidenriched dairy product on the blood pressure of spontaneously hypertensive and normotensive Wistar-Kyoto rats. Br J Nutr 2004;92:411-7. https://doi.org/10.1079/bjn20041221.

24. Park S, Lee KH, Kang WS, Kim JS, Kim S. Endothelium-dependent and endothelium-independent vasorelaxant effects of unripe Rubus coreanus Miq. and Dendropanax morbiferus H. Lév. extracts on rat aortic rings. BMC Complement Med Ther. 2020;20(1):190. https://doi.org/10.1186/ s12906-020-02977-6.

25. Ahmad M, Masood S, Sultana S, Hadda TB, Bader A, Zafar M. Report: antioxidant and nutraceutical value of wild medicinal Rubus berries. Pak J Pharm Sci. 2015;28(1):241-7 https://www.ncbi.nlm.nih.gov/pubmed/ 25553701.

26. Moon GS. Constituents and uses of medicinal herbs. Seoul, Korea: Ilweolseogak; 1991. p. 310-1.

27. Panchal SK, Ward L, Brown L. Ellagic acid attenuates high-carbohydrate, high-fat diet-induced metabolic syndrome in rats. Eur J Nutr 2013:52(2):559-568. https://doi.org/10.1007/s00394-012-0358-9.

28. Bobinaite R, Viškelis P, Venskutonis PR. Variation of total phenolics, anthocyanins, ellagic acid and radical scavenging capacity in various raspberry (Rubus spp.) cultivars. Food Chem 2012;132(3):1495-1501. https://doi. org/10.1016/j.foodchem.2011.11.137.

29. Yang HM, Oh SM, Lim SS, Shin HK, Oh YS, Kim JK. Antiinflammatory activities of Rubus coreanus depend on the degree of fruit ripening. Phytother Res 2008;22(1):102-107. https://doi.org/10.1002/ptr.2274.

30. Jung M-A, Cho S-H, Lee SY, et al. Effects of unripe Rubus coreanus Miquel extract on improvement of lipid metabolism in C57BL/6 mice fed a highcholesterol diet, J Korean Soc Food Sci Nutr 2014;43:650-655. https://doi. org/10.3746/jkfn.2014.43.5.650.

31. Lee $\mathrm{KH}$, Jeong $\mathrm{E}$, Jang $\mathrm{G}$, et al. Unripe Rubus coreanus Miquel extract containing ellagic acid regulates AMPK, SREBP-2, HMGCR and INSIG-1 
signaling and cholesterol metabolism in vitro and in vivo. Nutrients 2020;12(3):610. https://doi.org/10.3390/nu12030610.

32. Jung M-A, Cho S-H, Lee SY, et al. Anti-obesity effects on unripe Rubus coreanus Miquel extract in high fat diet-induced obese mice. IJBCRR. 2014:5:20-6. https://doi.org/10.9734/JJBCRR/2015/12680.

33. Oh DR, Kim Y, Choi EJ, et al. Antiobesity effects of unripe Rubus coreanus Miquel and its constituents: an in vitro and in vivo characterization of the underlying mechanism, Evid Based Complement Alternat Med 2016:2016:4357656. https://doi.org/10.1155/2016/4357656.

34. The European Parliament and the Council of the European Union. Directive 2010/63/EU of the European parliament and of the council of 22 September 2010 on the protection of animals used for scientific purposes. Off J Eur Union. 2010;276:33-79 https://eur-lex.europa.eu/LexUr iServ/LexUriServ.do?uri=OJ:L:2010:276:0033:0079:EN:PDF.

35. Goldblatt H, Lynch J, Hanzal RF, Summerville WW. Studies on experimental hypertension : I. Thr production of persistent elevation of systolic blood pressure by means of renal ischemia. J Exp Med 1934;59(3):347379. https://doi.org/10.1084/jem.59.3.347.

36. Laffan RJ, Goldberg ME, High JP, Schaeffer TR, Waugh MH, Rubin B. Antihypertensive activity in rats for SQ 14,225, an orally active inhibitor of angiotensin I-converting enzyme. J Pharmacol Exp Ther. 1978;204(2):281-8 http://jpet.aspetjournals.org/content/204/2/281.

37. McCaa RE, McCaa CS, Bengis RG, Guyton AC. Role of aldosterone in experimental hypertension. J Endocrinol. 1979;81(2):69-78.

38. Okamoto K, Aoki K. Development of a strain of spontaneously hypertensive rats. Jpn Circ J 1963;27:282-293. https://doi.org/10.1253/jcj.27.282.

39. Duarte J, Pérez-Palencia R, Vargas F, et al. Antihypertensive effects of the flavonoid quercetin in spontaneously hypertensive rats. Br J Pharmacol 2001;133(1):117-124. https://doi.org/10.1038/sj.bjp.0704064.

40. Rees DD, Palmer RM, Moncada S. Role of endothelium-derived nitric oxide in the regulation of blood pressure. Proc Natl Acad Sci U S A 1989:86(9):3375-3378. https://doi.org/10.1073/pnas.86.9.3375.

41. Vallance P, Collier J, Moncada S. Effects of endothelium-derived nitric oxide on peripheral arteriolar tone in man. Lancet 1989;2(8670):9971000. https://doi.org/10.1016/s0140-6736(89)91013-1.

42. Palmer RM, Ashton DS, Moncada S. Vascular endothelial cells synthesize nitric oxide from ${ }_{L}$-arginine. Nature 1988;333(6174):664-666. https://doi. org/10.1038/333664a0.

43. Palmer RM, Ferrige AG, Moncada S. Nitric oxide release accounts for the biological activity of endothelium-derived relaxing factor. Nature 1987;327(6122):524-526. https://doi.org/10.1038/327524a0.

44. Shesely EG, Maeda N, Kim HS, et al. Elevated blood pressures in mice lacking endothelial nitric oxide synthase. Proc Natl Acad Sci U S A 1996;93(23):13176-13181. https://doi.org/10.1073/pnas.93.23.13176.

45. Böger RH, Bode-Böger SM. The clinical pharmacology of ${ }_{L}$-arginine. Annu Rev Pharmacol Toxicol 2001;41:79-99. https://doi.org/10.1146/annurev. pharmtox.41.1.79.

46. Evans RW, Fernstrom JD, Thompson J, Morris SM Jr, Kuller LH. Biochemical responses of healthy subjects during dietary supplementation with L-arginine. J Nutr Biochem 2004;15(9):534-539. https://doi.org/10.1016/j. jnutbio.2004.03.005.

47. Preli RB, Klein KP, Herrington DM. Vascular effects of dietary L-arginine supplementation. Atherosclerosis 2002;162(1):1-15. https://doi.org/10. 1016/s0021-9150(01)00717-1.

48. Lee CW, Li D, Channon KM, Paterson DJ. -arginine supplementation reduces cardiac noradrenergic neurotransmission in spontaneously hypertensive rats. J Mol Cell Cardiol 2009;47(1):149-155. https://doi.org/ 10.1016/j.yjmcc.2009.03.023.

49. Ryu WS, Kim SW, Kim CJ. Overview of the renin-angiotensin system. Korean Circ J 2007:37(3):91-96. https://doi.org/10.4070/kcj.2007.37.3.91.

50. Sridevi P, Prashanth KS, Bhagavan RM. Angiotensin converting enzyme: a target for anti-hypertensive drugs. Int I Res Pharm Biomed Sci. 2011;2(1):63-72

51. Kim S, Iwao H. Molecular and cellular mechanisms of angiotensin II-mediated cardiovascular and renal diseases. Pharmacol Rev. 2011;52:12-30 http://pharmrev.aspetjournals.org/content/52/1/11.

52. Benigni $A$, Cassis $P$, Remuzzi G. Angiotensin II revisited: new roles in inflammation, immunology and aging. EMBO Mol Med 2010;2:247-257. https://doi.org/10.1002/emmm.201000080.

53. Weber DS, Rocic P, Mellis AM, et al. Angiotensin II-induced hypertrophy is potentiated in mice overexpressing p22phox in vascular smooth muscle.
Am J Physiol Heart Circ Physiol 2005;288(1):H37-H42. https://doi.org/10. 1152/ajpheart.00638.2004.

54. Chobanian AV, Bakris GL, Black HR, et al. The seventh report of the joint national committee on prevention, detection, evaluation, and treatment of high blood pressure: the JNC 7 report. JAMA. 2003;289(19):2560-2572. https://doi.org/10.1001/jama.289.19.2560.

55. Hernández-Ledesma B, del Mar Contreras M, Recio I. Antihypertensive peptides: production, bioavailability and incorporation into foods. Adv Colloid Interf Sci 2011;165(1):23-35. https://doi.org/10.1016/j.cis.2010.11. 001.

56. Campbell DJ, Duncanm AM, Kladism A, Harrap SB. Angiotensin peptides in spontaneously hypertensive and normotensive Donryu rats. Hypertension. 1995;25(5):928-934. https://doi.org/10.1161/01.hyp.25.5.928.

57. Lee RM, Berecek KH, Tsoporis J, McKenzie R, Triggle CR. Prevention of hypertension and vascular changes by captopril treatment. Hypertension. 1991;17(2):141-150. https://doi.org/10.1161/01.hyp.17.2.141.

58. Takai S, Jin D, Sakaguchi M, Miyazaki M. Significant target organs for hypertension and cardiac hypertrophy by angiotensin-converting enzyme inhibitors. Hypertens Res 2004;27(3):213-219. https://doi.org/10. 1291/hypres.27.213.

59. Stepien M, Witte K, Lemmer B. Chronobiologic evaluation of angiotensinconverting enzyme activity in serum and lung tissue from normotensive and spontaneously hypertensive rats. Chronobiol Int 1993;10(5):331-337. https://doi.org/10.3109/07420529309064487.

60. Kuriyama K, Sze PY. Blood-brain barrier to H3- $\gamma$-aminobutyric acid in normal and amino oxyacetic acid-treated animals. Neuropharmacology 1971;10(1):103-108. https://doi.org/10.1016/0028-3908(71)90013-x.

61. Kleiber M. Body size and metabolism. Hilgardia 1932;6(11):315-353. https://doi.org/10.3733/hilg.v06n11p315.

62. Kleiber M. The fire of life. An introduction to animal energetics. New York: Wiley; 1961. p. xxii-454.

63. Wang X, Desai K, Juurlink BH, de Champlain J, Wu L. Gender-related differences in advanced glycation endproducts, oxidative stress markers and nitric oxide synthases in rats. Kidney Int 2006;69(2):281-287. https://doi. org/10.1038/sj.ki.5000043.

64. Wu CC, Hong HJ, Chou TC, Ding YA, Yen MH. Evidence for inducible nitric oxide synthase in spontaneously hypertensive rats. Biochem Biophys Res Commun 1996;228(2):459-466. https://doi.org/10.1006/bbrc.1996.1682.

65. Chou TC, Yen MH, Li C Y, Ding YA. Alterations of nitric oxide synthase expression with aging and hypertension in rats. Hypertension 1998;31(2):643-648. https://doi.org/10.1161/01.hyp.31.2.643.

66. Zalba G, Beaumont FJ, San José G, et al. Vascular NADH/NADPH oxidase is involved in enhanced superoxide production in spontaneously hypertensive rats. Hypertension 2000;35(5):1055-1061. https://doi.org/10.1161/01. hyp.35.5.1055.

67. Griendling KK, Minieri CA, Ollerenshaw JD, Alexander RW. Angiotensin II stimulates NADH and NADPH oxidase activity in cultured vascular smooth muscle cells. Circ Res 1994;74(6):1141-1148. https://doi.org/10. 1161/01.res.74.6.1141.

68. Rajagopalan S, Kurz S, Münzel T, et al. Angiotensin II-mediated hypertension in the rat increases vascular superoxide production via membrane NADH/NADPH oxidase activation. Contribution to alterations of vasomotor tone. J Clin Invest 1996;97(8):1916-1923. https://doi.org/10.1172/ JCl118623.

69. Wind $\mathrm{S}$, Beuerlein $\mathrm{K}$, Armitage ME, et al. Oxidative stress and endothelial dysfunction in aortas of aged spontaneously hypertensive rats by NOX $1 / 2$ is reversed by NADPH oxidase inhibition. Hypertension 2010;56(3):490-497. https://doi.org/10.1161/HYPERTENSIONAHA.109. 149187.

70. Sánchez M, Galisteo M, Vera R, et al. Quercetin downregulates NADPH oxidase, increases eNOS activity and prevents endothelial dysfunction in spontaneously hypertensive rats. J Hypertens 2006;24(1):75-84. https:// doi.org/10.1097/01.hjh.0000198029.22472.d9.

71. Xu L, Liu Y. Administration of telmisartan reduced systolic blood pressure and oxidative stress probably through the activation of PI3K/Akt/eNOS pathway and NO release in spontaneously hypertensive rats. Physiol Res. 2013;62(4):351-9.

72. Chou TC, Yen MH, Li CY, Ding YA. Alterations of nitric oxide synthase expression with aging and hypertension in rats. Hypertension 1998;31(2):643-648. https://doi.org/10.1161/01.hyp.31.2.643. 
73. Zecchin HG, Bezerra RM, Carvalheira JB, et al. Insulin signalling pathways in aorta and muscle from two animal models of insulin resistance--the obese middle-aged and the spontaneously hypertensive rats. Diabetologia. 2003;46(4):479-491. https://doi.org/10.1007/s00125-003-1073-0.

74. Yang D, Luo Z, Ma S, et al. Activation of TRPV1 by dietary capsaicin improves endothelium-dependent vasorelaxation and prevents hypertension. Cell Metab 2010;12(2):130-141. https://doi.org/10.1016/j.cmet. 2010.05.015.

75. Adcock IM, Brown CR, Kwon O, Barnes PJ. Oxidative stress induces NFKB DNA binding and inducible NOS mRNA in human epithelial cells.
Biochem Biophys Res Commun 1994;199(3):1518-1524. https://doi.org/ 10.1006/bbrc.1994.1403.

\section{Publisher's Note}

Springer Nature remains neutral with regard to jurisdictional claims in published maps and institutional affiliations.
Ready to submit your research? Choose BMC and benefit from:

- fast, convenient online submission

- thorough peer review by experienced researchers in your field

- rapid publication on acceptance

- support for research data, including large and complex data types

- gold Open Access which fosters wider collaboration and increased citations

- maximum visibility for your research: over $100 \mathrm{M}$ website views per year

At BMC, research is always in progress.

Learn more biomedcentral.com/submissions 